\title{
Article \\ Risk Assessment of Terrestrial Transportation Infrastructures Exposed to Extreme Events
}

\author{
Unni Eidsvig 1,*®D, Monica Santamaría ${ }^{2}$, Neryvaldo Galvão ${ }^{2}$, Nikola Tanasic ${ }^{3}$, Luca Piciullo ${ }^{1}$, Rade Hajdin ${ }^{3}$, \\ Farrokh Nadim ${ }^{1}$, Hélder S. Sousa ${ }^{2}$ id and José Matos ${ }^{2}$ \\ 1 Natural Hazards Division, Norwegian Geotechnical Institute (NGI), N-0806 Oslo, Norway; \\ Luca.Piciullo@ngi.no (L.P.); Farrokh.Nadim@ngi.no (F.N.) \\ 2 Department of Civil Engineering, Institute for Sustainability and Innovation in Structural Engineering (ISISE), \\ University of Minho, 4800-058 Guimarães, Portugal; id8021@alunos.uminho.pt (M.S.); \\ id8023@alunos.uminho.pt (N.G.); hssousa@civil.uminho.pt (H.S.S.); jmatos@civil.uminho.pt (J.M.) \\ 3 Infrastructure Management Consultants Gmbh (IMC), 8008 Zürich, Switzerland; \\ nikola.tanasic@imc-de.com (N.T.); rade.hajdin@imc-ch.com (R.H.) \\ * Correspondence: uke@ngi.no
}

check for updates

Citation: Eidsvig, U.; Santamaría, M.; Galvão, N.; Tanasic, N.; Piciullo, L.; Hajdin, R.; Nadim, F.; Sousa, H.S.;

Matos, J. Risk Assessment of

Terrestrial Transportation Infrastructures Exposed to Extreme Events. Infrastructures 2021, 6, 163. https: / / doi.org/10.3390/

infrastructures6110163

Academic Editor: Belen Riveiro

Received: 22 October 2021

Accepted: 12 November 2021

Published: 17 November 2021

Publisher's Note: MDPI stays neutral with regard to jurisdictional claims in published maps and institutional affiliations.

Copyright: (C) 2021 by the authors Licensee MDPI, Basel, Switzerland. This article is an open access article distributed under the terms and conditions of the Creative Commons Attribution (CC BY) license (https:// creativecommons.org/licenses/by/ $4.0 /)$.

\begin{abstract}
Keeping transport links open in adverse conditions and being able to restore connections quickly after extreme events are important and demanding tasks for infrastructure owners/operators. This paper is developed within the H2020 project SAFEWAY, whose main goal is to increase the resilience of terrestrial transportation infrastructure. Risk-based approaches are excellent tools to aid in the decision-making process of planning maintenance and implementation of risk mitigation measures with the ultimate goal of reducing risk and increasing resilience. This paper presents a framework for quantitative risk assessment which guides an integrated assessment of the risk components: hazard, exposure, vulnerability and consequences of a malfunctioning transportation infrastructure. The paper guides the identification of failure modes for transportation infrastructure exposed to extreme events (natural and human-made) and provides models for and examples of hazard, vulnerability and risk assessment. Each assessment step must be made in coherence with the other risk components as an integral part of the risk assessment.
\end{abstract}

Keywords: risk assessment; natural hazards; extreme events; terrestrial transportation infrastructures; vulnerability; resilience

\section{Introduction}

Efficient and secure transport networks are essential to the modern society. They ensure transportation of goods and people as well as access to employment and to essential services such as education, health care and emergency services. Keeping transport links open in adverse conditions and being able to restore connections quickly after extreme events are important and demanding tasks [1]. Many different types of adverse weather conditions challenge transportation networks such as intense precipitation [2], extreme temperatures [3], storms [4], floods [5], erosion, landslides [6-8], avalanches [9] and forest fires [10]. Climate change is anticipated to lead to an escalation of natural extreme events, both in frequency and magnitude [11,12]. In addition, human-made extreme events such as collisions [13,14], explosions [15], suicides on transportation lines, arson and terrorist attacks [16] pose a threat to transportation networks. Consequences of extreme events include accidents, damage to infrastructure assets, delays and malfunctioning of the transportation network, resulting in socio-economic losses and adverse environmental impacts [17-19]. The available funds for operation, maintenance and climate adaptation measures are limited, and it is important to make well-founded priorities. Thus, risk-based approaches are increasingly being applied to aid in the decision-making process of planning maintenance and prioritizing risk mitigation measures [20-22]. Here, the main tasks are to 
identify the most vulnerable assets and prioritize measures and resources according to the available budget. Despite the implementation of state-of-the-art maintenance programs and risk mitigation measures, failures of infrastructure may still occur. Thus, it is necessary to also prepare for the recovery phase after failure.

\subsection{Risk Assessment of Terrestrial Transportation Infrastructures in the Literature}

The ISO framework [23] escribes risk identification (i.e., adverse events that may occur and what may trigger them) as the first step in a risk management process. This assessment step is however scarcely described in risk assessment examples of terrestrial transportation infrastructures in the literature. Application examples usually start with a risk assessment of a specific adverse event, e.g., [2]-omitting the screening of all threats. There is a lack of studies that describe the identification of risk scenarios as part of the risk assessment framework, in a similar way that [22] describes holistic methods for risk evaluation of bridges. Existing overviews of adverse events for transportation infrastructure leading to structural damage and/or service disruptions consist of detailed lists $[11,17,24]$. However, these overviews are not exhaustive, and their use is also not presented as a part of the risk assessment. There is therefore a need to take a step back and present the identification of the risk scenarios in a more general way-to support the definition of the scope of the risk assessment.

General risk assessment frameworks (e.g., $[23,25])$ comprise assessing the hazard and vulnerability / fragility of the exposed elements/assets. However, practical challenges with concretization and conceptualization of the risk assessment steps arise when adopting these frameworks to specific applications. For instance, the Italian guidelines on risk classification and management of existing bridges group bridges into risk classes for prioritization of detailed assessment and funds allocation. Nevertheless, the application of the framework to real road networks has been found to provide conservative results and do not enable the ranking of bridges belonging to the same class given their qualitative nature [21]. Other risk assessment literature considers transport infrastructure specifically but treats the risk semi-quantitatively (e.g., [6,26]) and is focused on a specific hazard type (e.g., [27]) and/or a specific asset (e.g., [20]). Research efforts have been conducted in recent years to formulate methodologies capable of integrating all risk components effectively and reliably. A predominant part of this research has focused on the development of methodologies for risk quantification of bridge networks subjected to seismic ground motion [28,29]. Some work has been done for other types of natural hazards such as flooding and floodinduced scour [22,30]. Impacts of climate change on the intensity and frequency of the extreme events have also received attention and have been integrated into the hydrological modelling step within risk assessment frameworks [20,31].

In addition, given the possibility of infrastructure systems to experience multiple hazards, research interest has emerged towards the development of risk assessment methodologies to investigate the effect of interacting hazards such as rainfall-induced floods and mudflows [2] and earthquake-induced tsunami [32,33]. However, for other types of multi-hazard interactions, only the performance of bridges under these events have been studied since the risk analysis at the transportation system level requires spatial and temporal modelling of complex phenomena. Moreover, vulnerability models for other types of infrastructure assets such as road segments, pavements, tunnels, retaining walls, embankments and slopes are rather limited [34]. Thus, most risk assessment methodologies are demonstrated with real transportation networks yet select few bridges as primary vulnerable elements and neglect the damage to other network components.

Fragility functions have been widely applied in probabilistic risk and vulnerability assessment for buildings, in particular for earthquake risk (Hazus n.d.), but recently also for landslide risk assessment. Fragility functions have also been used for assessment of probability of damage to transportation infrastructure assets and service disruptions caused by landslides, debris-earth flow and flooding and for assessment of the combined effects of scouring and earthquakes for bridges, e.g., in [2,5,7,8,35-40]. An overview of the content 
of these (and other vulnerability functions) is provided in Section 2.3.2. However, these functions only cover a subset of assets, failure modes and extreme events.

\subsection{Scope of the Paper}

The research presented in this paper was done within the H2020 project SAFEWAY, whose main goal is to increase the resilience of terrestrial transport infrastructure while minimizing long-term costs associated with maintenance and rehabilitation of the infrastructure. SAFEWAY aims to design and implement holistic methods, strategies, tools and technical interventions to strengthen terrestrial transportation network systems that are exposed to extreme events (natural and human-made). The project addresses reduction of vulnerabilities within:

- Preparation: by improving risk estimation and prediction and by developing better monitoring and decision tools;

- Response and recovery: by optimizing emergency plans and real-time communication with operators and end users;

- Mitigation: by introducing new construction systems and smart materials and by assessing consequences of different scenarios and mitigation solutions for selection of the optimal mitigation strategy.

The scope of this paper is to propose a framework for quantitative risk assessment of terrestrial transport infrastructures, integrating results from detailed analyses, application of existing models in the literature and external data sources, valid for:

1. Different levels of detail (regarding accuracy and complexity) and analysis scale (e.g., at asset level, within a transportation link or at network level);

2. Different types of infrastructure assets;

3. Natural extreme events (with focus on weather-related hazards) and unintentional human-made extreme events; (i.e., potentially disastrous events or disorders caused by human activity. Human errors [41] related to technical human activities are not included);

4. Assessment of structural damage and loss of mobility. The safety of the users is not considered directly, i.e., cases where road or railway users are directly injured by an extreme event are not considered, and the focus is on the infrastructure assets.

The proposed framework aims to bridge the gap between general risk assessment frameworks and specific risk assessments of terrestrial transportation infrastructures in literature (that focuses on specific risk component, on specific hazard types and/or specific assets).

The paper is organized in the following sections: Section 2 presents the development and conceptualization of the quantitative risk assessment framework, and application examples are provided in Section 3. Section 4 discusses limitations in the work done and the need for further work. Section 5 provides concluding remarks for the work.

\section{Risk Assessment of Terrestrial Transportation Systems-Conceptualization of the Assessment Steps}

The IS0 31000:2018 [23] represents a globally accepted standard for risk management, where risk assessment includes: risk identification, risk analysis and risk evaluation, and is followed by risk treatment (decision-making and execution of measures aimed at risk reduction). Risk assessment basically consists of finding answers to the following questions [25]:

1. What can cause harm? (Potential threats and adverse events are identified.)

2. How often may the identified adverse event occur? (What is the frequency of occurrence?)

3. What can go wrong? (Which are the exposed elements and what are the consequences?) 
4. If it goes wrong, how severe are the consequences? (The severity will depend on the robustness/resistance of the exposed elements/assets and the intensity of the hazard.)

If the assessed risk is considered intolerable or unacceptable, the next question would be: What should be done to reduce the risk to an acceptable level?

This section outlines a framework for the risk assessment for terrestrial transportation systems by answering these basic questions. The focus is on the quantitative assessment of the risk, expressing each of the risk components and their combination into risk quantitatively.

\subsection{What Can Cause Harm?}

The first step in the risk assessment is to specify the scope of the analysis, and a key question is "What can cause harm"? This question will consist of identifying risk scenarios encompassing plausible descriptions of how a structural damage of the infrastructure assets and/or a service disruption may occur (i.e., failure mode), as well as description of the triggering event. Identification of risk scenarios should be based on experiences from the past, but other plausible extreme events (natural and human-made hazards) and failure modes should also be considered.

Table 1 is provided as an element for a screening process for selection of hazard types and failure modes to be considered in the risk assessment regarding the scope specification. The focus was on the weather-related natural hazards and on the unintentional humanmade hazards. The selection of risk scenario(s) for further assessment can be made based on the most predominant hazard type in the study area and/or based on particularly vulnerable assets. Each of the failure modes in the table must be assessed separately following the steps in the risk assessment framework.

This paper suggests the arrangement of the failure modes/modes of malfunctioning into the following categories: (1) structural damage of transportation line assets, (2) material or obstacles (e.g., water, debris, objects) on the transportation line, (3) failure of supporting systems (signal system for trains, etc.) and (4) dangerous driving conditions, including precautionary closure (e.g., wind on bridges, forest fires, potential landslide hazard).

There could also be a chain of events over time that make the structure more prone to a certain failure mode or preconditioning events, which increases the probability of one or more of the failure modes listed in Table 1. For example: loss of vegetation (e.g., due to fire or drought) may lead to a decrease in slope stability and over time lead to slope failure. Other examples could be advanced deterioration or other slow hazards that over time causes failure. 
Table 1. Overview of failure modes/modes of malfunctioning triggered by extreme events, classified into main categories (n.a. $=$ not applicable).

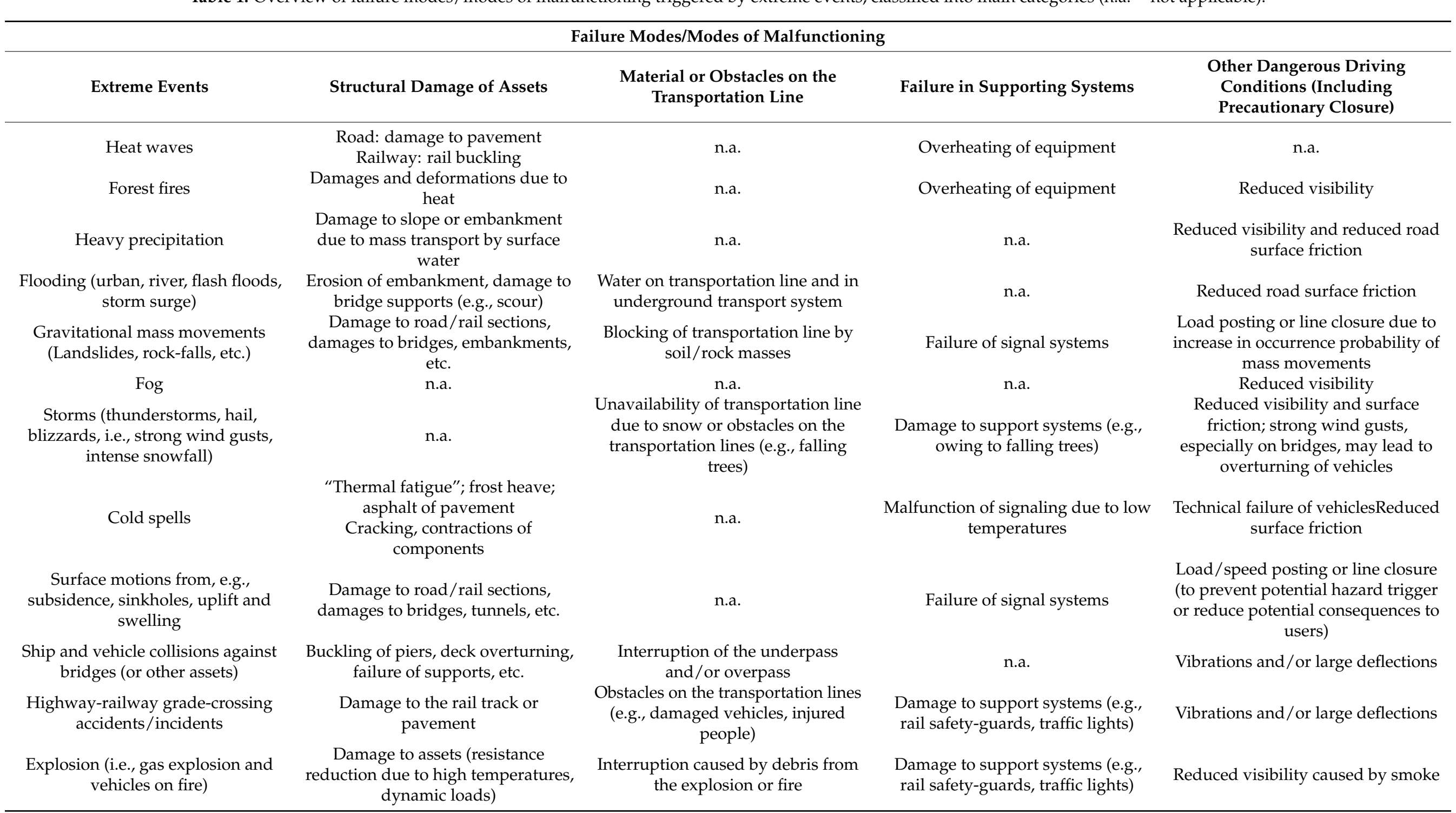




\subsection{How Often May the Identified Adverse Event Occur?}

This question is related to both the frequency or the temporal probability of the triggering extreme event and the conditional probability of structural damage of infrastructure assets and/or a service disruption (i.e., failure mode) in case of an extreme event.

Let:

- $\quad F M$ be the failure mode of interest. The failure mode describes the severity of structural damage and/or functional loss, due to an extreme event;

- $E E_{i}$ be the extreme event of interest that could trigger the failure mode;

- $\quad i$ represent the intensity of the extreme event $E E_{i}$. The intensity is a single or a composite parameter expressing a damaging potential/action of the extreme event at asset(s) location;

- $\quad P_{\text {temporal }}$ denote the temporal probability, e.g., annual probability expressing the occurrence probability per year.

The temporal probability of $F M$ when considering a specific intensity value is the product of $P_{\text {temporal }}\left(E E_{i}\right)$ and $P\left(F M \mid E E_{i}\right)$. For assessment of the temporal probability of the failure mode, all intensity values need to be considered and their contributions summed:

$$
P_{\text {temporal }}(F M)=\sum_{\text {All } \mathrm{i}} P_{\text {temporal }}(E E i) \cdot P(F M \mid E E i)
$$

The term $P_{\text {temporal }}\left(E E_{i}\right)$ expresses the temporal probability (typically the annual probability) of the extreme event, with a certain intensity, which is referred to as the hazard. For a specific geographical position, the hazard can be represented as a curve, i.e., as a mathematical function of the relationship between intensity and return period of the hazard (e.g. as described in Section 3.1.2). However, for practical design, the hazard curve is assessed at discrete return periods specified in the design code. Hazard assessment for an area would then comprise hazard zoning or hazard mapping, visualizing the spatial intensity distribution of the hazard on maps.

In general, the probability of an event might be estimated using three main strategies, separately, or in combination: (i) statistical analysis of historical events, e.g., by the use of extreme event analysis such as Gumbel, to analyze meteorological, geological, hydrological, agricultural, environmental and epidemiological data statistically in natural hazards assessment [42]; (ii) models expressing the occurrence of the event, considering also the uncertainty in the model parameters, e.g., by use of a geotechnical model in probabilistic slope stability analysis for slope-specific precipitation-induced landslide hazard assessment; and (iii) use of expert judgment, relating the probability to the degree-of-belief based on knowledge and intuition, e.g., by use of heuristic models for regional landslide hazard assessment [43].

The term $P\left(F M \mid E E_{i}\right)$ expresses the probability of FM in case of an extreme event with intensity $i$. For the different failure modes described in Table 1, this term would typically express the probability of:

- Structural damage to the asset, e.g., a partial failure or an asset collapse;

- Material or obstacles on the transportation line leading to service disruption, e.g., in terms of capacity reductions (e.g., a \% of total capacity at an analyzed road section), speed reductions or load postings (e.g., a bridge is closed for freight traffic);

- Failure of supporting systems, where the definition of failure is contained within the detailed failure mode description;

- Dangerous driving conditions leading to restrictions, usually defined as thresholds on intensity parameters.

These probabilities will be assessed by using mathematical models for vulnerability assessment addressed in Section 2.3.2. 


\subsection{What Can Go Wrong?}

In this step, the exposed elements and potential consequences are identified. Following the conceptualization of Section 2.2, the exposed elements are the assets or parts of the infrastructure, for which $i>0$. The exposure assessment is a prerequisite to define the possible simultaneous failures of assets and other combinations of failures in the network. Bridges and tunnels are key assets in a terrestrial transport network. Their non-availability will directly lead to a service disruption on the transportation line. For other assets, the structural asset damage would not cause a service disruption, e.g., damages to the pavement.

\subsubsection{Assessment of Exposure}

For natural hazards, the exposed infrastructure assets can be identified as the geographical coincidence between the hazard and the location of the asset (Figure 1).

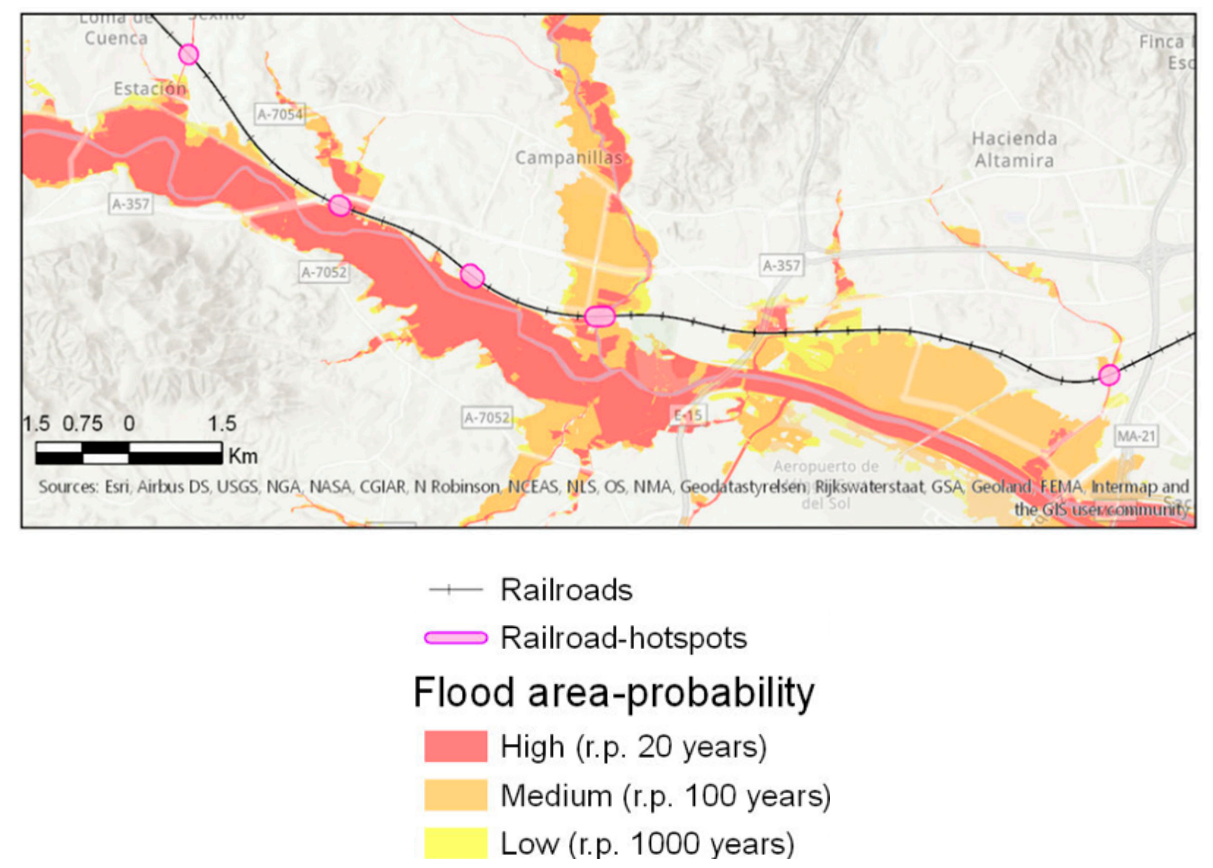

Figure 1. Exposure of railway track to floods for different flood return periods (20-years, 100-years and 1000-years) within the Málaga region, Spain. The exposed parts of the railway are indicated with pink ellipses. (Source: [44]).

Users, economic activity and the environment can be indirectly exposed to the event due to failures of related infrastructure assets, something accounted for in the consequence assessment (Section 2.4).

For unintentional human-made hazards, exposure maps as shown in Figure 1 are difficult to develop because it is unfeasible to predict spatial distribution of human-made events. However, one might identify locations with a higher likelihood for occurrence of such events, e.g., points more prone to collision (i.e., bridge crossing a river or seaway of high traffic) or other accidents.

The unintentional vehicle collision hazard is usually characterized by its intensity (in terms of collision force) and temporal probability [13]. An equivalent static design force of $2670 \mathrm{kN}$ when a resistance design is concerned is suggested by [45]. Nonetheless, if the annual probability of collision occurrence concerning heavy vehicles is lower than $1.0 \times 10^{-4}$ for critical bridges and $1.0 \times 10^{-3}$ for typical bridges, resistance design for vehicle collision is not required. The annual probability for a bridge pier to be struck by a heavy vehicle depends on the expected average daily traffic, the share of heavy vehicles and characteristics of the road where the investigated bridge is located. 


\subsubsection{Assessing the Conditional Probability of Failure Modes}

The potential consequences are described through the failure modes. Mathematical models for vulnerability assessment allow estimation of both direct and indirect consequences for a range of hazard intensities, through the definition of failure modes [46]. In estimation of direct material consequences, e.g., potential damage(s) to physical assets, damage or loss functions are often applied, describing the structural damage or functional loss of the asset (e.g., a bridge is closed until the inspection/repairs are finished). These functions take into account the hazard intensity and the structural resistance of asset(s) to the loads resulting from the related hazard action [47-49]. The structural damage is often described as the degree of loss on a dimensionless $0-1$ scale.

Alternatives to damage and loss functions are fragility functions, which also express the uncertainty in the damage or functional loss. These functions describe the probability of exceeding different damage states for various hazard intensities [50]. The probability of damage or thresholds in a hazard intensity for different damage levels could also be described in terms of tables that specify the failure probability for different load conditions. Such tables represent discrete points on a fragility curve.

The probability $P\left(F M \mid E E_{i}\right)$ from Equation (1) could be found directly from fragility functions or fragility tables, if such models are available for the failure mode FM (e.g., as developed in Section 3.2. If damage functions are applied, the following strategy for calculation of $P(F M \mid E E i)$ may be applied:

Let:

- $S D(F M)$ be the degree of structural damage of the asset(s) in the failure mode;

- $S D_{\text {calc }}$ be the structural damage estimated from the damage functions.

For failure modes involving structural damage, Equation (2) yields:

$$
P\left(F M \mid E E_{i}\right)=\left\{\begin{array}{l}
1, \text { if } S D_{\text {calc }} \geq S D(F M) \\
0, \text { if } S D_{\text {calc }}<S D(F M)
\end{array} .\right.
$$

Similarly, for failure modes, where dangerous driving conditions are defined by the intensity exceeding a threshold $T$, Equation (3) yields:

$$
P\left(F M \mid E E_{i}\right)=\left\{\begin{array}{l}
1, \text { if } i \geq T \\
0, \text { if } i<T
\end{array} .\right.
$$

A review of existing damage, loss and fragility functions has been conducted for both natural and human-made hazards. As the availability of such functions is limited in literature, the reviewed extreme events and related failure modes/modes of malfunctioning cover a subset of all the aspects from Table 1 . Table 2 provides a summary of the review.

Table 2. Damage, loss and fragility models from the literature for different extreme events and failure modes/modes of malfunctioning (n.a. = not available).

\begin{tabular}{cccc}
\hline & Overview of Available Damage, Loss and Fragility Models & \\
\hline Extreme Event & Structural Damage of Assets & $\begin{array}{c}\text { Material or Obstacles on the } \\
\text { Transportation Line }\end{array}$ & $\begin{array}{c}\text { Dangerous Driving } \\
\text { Conditions (Including } \\
\text { Precautionary Closure) }\end{array}$ \\
\hline Heat waves & $\begin{array}{c}\text { Temperature threshold models for rail } \\
\text { buckling: [3,51-53] }\end{array}$ & n.a. & $\begin{array}{c}\text { Probability of adverse events } \\
\text { for different threshold values of } \\
\text { temperature: [54] }\end{array}$ \\
$\begin{array}{c}\text { Flooding (urban, river, flash } \\
\text { floods, storm surge) }\end{array}$ & $\begin{array}{c}\text { Bridge scour leading to bridge failure: } \\
{[35-37,55]}\end{array}$ & $\begin{array}{c}\text { Vehicle speed as function of } \\
\text { floodwater depth: [5] } \\
\text { Functional capacity loss } \\
\text { functions as a function of } \\
\text { inundation depth: [2,7] }\end{array}$ & $\begin{array}{c}\text { Thresholds for vehicle stability } \\
\text { in floods: [57] }\end{array}$ \\
\hline
\end{tabular}


Table 2. Cont.

\begin{tabular}{|c|c|c|c|}
\hline \multicolumn{4}{|c|}{ Overview of Available Damage, Loss and Fragility Models } \\
\hline Extreme Event & Structural Damage of Assets & $\begin{array}{l}\text { Material or Obstacles on the } \\
\text { Transportation Line }\end{array}$ & $\begin{array}{l}\text { Dangerous Driving } \\
\text { Conditions (Including } \\
\text { Precautionary Closure) }\end{array}$ \\
\hline Landslides & Material damage to roads: $[9,56]$ & $\begin{array}{l}\text { Malfunctioning due to debris } \\
\text { on roads as a function of } \\
\text { landslide volume: [8] }\end{array}$ & n.a. \\
\hline Storms & n.a. & $\begin{array}{l}\text { Probability of adverse events } \\
\text { for different threshold values of } \\
\text { wind speed: [54] }\end{array}$ & $\begin{array}{l}\text { Threshold models for wind } \\
\text { speed on bridges: [53] }\end{array}$ \\
\hline $\begin{array}{c}\text { Ship and vehicle collisions } \\
\text { against bridges }\end{array}$ & $\begin{array}{l}\text { Vehicle collision with bridge piers: [58] } \\
\text { Vehicle collision with bridge piers: A } \\
\text { state-of-the-art review: [13] } \\
\text { Nonlinear finite element analysis of barge } \\
\text { collision with a single bridge pier: [14] }\end{array}$ & 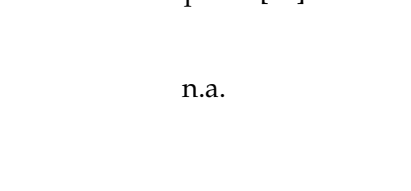 & n.a. \\
\hline $\begin{array}{l}\text { Highway-rail grade-crossing } \\
\text { accidents/incidents }\end{array}$ & $\begin{array}{l}\text { A comprehensive assessment of the } \\
\text { existing accident and hazard prediction } \\
\text { models for the highway-rail grade } \\
\text { crossings in the state of Florida: [59]. }\end{array}$ & n.a. & n.a. \\
\hline $\begin{array}{l}\text { Explosion (i.e., gas explosion), } \\
\text { bombing and vehicles on fire }\end{array}$ & $\begin{array}{l}\text { Vulnerability of bridges to fire: [16] } \\
\text { Analysis of a bridge failure due to fire } \\
\text { using computational fluid dynamics and } \\
\text { finite element models: [60] } \\
\text { Analysis of a bridge collapsed by } \\
\text { accidental blast loads: [15] }\end{array}$ & n.a. & n.a. \\
\hline
\end{tabular}

2.3.3. Recommendations for Development/Adaptation of Structural and Functional Vulnerability Functions

The review of vulnerability functions summarized in Table 2 indicates a lack of vulnerability functions in literature for several failure modes and extreme events. Nonetheless, existing vulnerability functions should also be used with caution. Significant variabilities for assets exist across different countries, and different classes of assets are encountered depending on the classification of the transport system [34]. Prior to the vulnerability assessment, one of the following steps should be accomplished:

1. Verification of existing fragility functions to site-specific conditions, i.e., by examining if the available fragility function appropriately represents the behavior of the asset types representative of the study area.

2. Adaptation of existing fragility functions to site-specific conditions, i.e., by calibrating the existing fragility function to observational data or by combining an existing fragility curve with observational data through Bayesian updating.

3. Development of new fragility functions based on recommended intensity parameters in Table 3 and using one of the four main approaches to develop vulnerability models [49]:

Judgmental: based on expert opinion or engineering judgement.

Empirical: based on observations.

Analytical: based on analytical or numerical solution methods.

Hybrid approach: combining one or more of above approaches.

For development of fragility curves for assets, analytical approaches validated by experimental data and observations from recent events have become more popular. According to [49], the analytical approach is the most commonly encountered in the peer-reviewed literature. This approach could be applied to different structure types and geographical regions, where damage records are insufficient. Functions describing degree of loss are mainly based on empirical data collected in the field in the aftermath of an event and are consequently specific to the exposed elements in the area where the data have been collected [50]. 
Table 3. Summary of the main parameters for vulnerability and risk analysis.

\begin{tabular}{|c|c|c|c|}
\hline \multicolumn{2}{|c|}{ Extreme Event/Hazard } & \multicolumn{2}{|r|}{ Asset } \\
\hline Type & Modelling Variable & Type & Failure Mode \\
\hline Flooding & Water discharge & Bridge & $\begin{array}{l}\text { Bridge scour leading to bridge failure } \\
\text { Failure of culvert leading to water }\end{array}$ \\
\hline Flooding & Water discharge & Culvert & $\begin{array}{l}\text { overtopping and material damage to } \\
\text { road/rail }\end{array}$ \\
\hline Flooding & Water discharge & Embankment & Failure of embankment caused by erosion \\
\hline Flooding & Water discharge & Roadway or rail track & Wash-out of roadway/rail track \\
\hline Rainfall/urban flooding & Water depth & Roadway & $\begin{array}{l}\text { Speed and capacity reductions/service } \\
\text { disruption due to water on road }\end{array}$ \\
\hline Flooding & Volume of debris & Roadway or rail track & $\begin{array}{l}\text { Speed and capacity reductions/service } \\
\text { disruption due to debris on road/track } \\
\text { after flooding }\end{array}$ \\
\hline Landslide & Volume of landslides & Roadway or rail track & $\begin{array}{c}\text { Speed and capacity reductions/service } \\
\text { disruption due to landslide masses on } \\
\text { road/track }\end{array}$ \\
\hline Heatwave & Temperature & Rail track & $\begin{array}{l}\text { Speed reductions of trains to avoid } \\
\text { buckling of tracks }\end{array}$ \\
\hline Wind & $\begin{array}{l}\text { Wind speed perpendicular } \\
\text { to the bridge }\end{array}$ & Bridge & Closed bridges due to strong wind gusts \\
\hline $\begin{array}{l}\text { Ship and vehicle } \\
\text { collisions against } \\
\text { bridges }\end{array}$ & Impact force & Bridge & Failure, collapse, damaged element \\
\hline $\begin{array}{l}\text { Highway-rail } \\
\text { grade-crossing } \\
\text { accidents/incidents }\end{array}$ & $\begin{array}{l}\text { Down time and restricted } \\
\text { lanes }\end{array}$ & Roadway or rail track & $\begin{array}{l}\text { Closed or traffic reduction/failure, collapse, } \\
\text { damaged element }\end{array}$ \\
\hline $\begin{array}{l}\text { Explosion (i.e., gas } \\
\text { explosion and vehicles } \\
\text { on fire) }\end{array}$ & Pressure-impulse & All types of assets & $\begin{array}{c}\text { Closed or traffic reduction/failure, collapse, } \\
\text { damaged element }\end{array}$ \\
\hline
\end{tabular}

Table 3 summarizes the failure modes for different asset types and extreme events with suggested main modelling variable for the vulnerability assessment.

\subsection{If It Goes Wrong: How Severe Are the Consequences?}

Economic consequences of extreme events on transportation infrastructure encompass direct consequences (e.g., structural damage, loss of life and limb e.g., [61]) as well as indirect consequences, which stem from the interruption of the transportation service (e.g., user costs due to additional travel time, socio-economic consequences due to the service disruption). The consequences could further be classified as associated to market values or not [19]. In the following, only consequences associated with market values are considered. Let:

- $\quad \mathrm{C}(F M), C_{\text {direct }}(F M)$ and $C_{\text {indirect }}(F M)$ denote the consequences, the direct consequences and the indirect consequences respectively associated with a failure mode $F M$, considering the full range of plausible intensities of $E E_{\mathrm{i}}$.

- $\quad R C$ be the full repair and reconstruction costs of the asset.

- $\quad C S$ be the costs of service disruption per hour.

- $D(F M)$ be the duration of the service disruption in hours associated with a failure mode FM.

Then:

$$
\mathrm{C}(F M)=C_{\text {direct }}(F M)+C_{\text {indirect }}(F M)
$$

To calculate the probability of a failure mode and related consequences caused by different natural hazards, it is suggested to use event trees or a Bayesian network. Guidance for such analyses is provided as an example in Section 3.3. 


\subsubsection{Assessment of Direct Consequences}

The damage, loss and fragility functions connects directly the intensity of a hazard with a failure mode, described in quantitative terms (e.g., damage degree of an asset, number of failed elements). This further enables monetization by including the value of affected assets. If $S D(F M)$ is expressed on a scale $0-1$, and the direct consequences refer to the costs for repair and reconstruction related to extreme events, Equation (5) yields:

$$
C_{\text {direct }}(F M)=S D(F M) \cdot R C
$$

Fragility functions can be converted into damage functions using a damage-to-loss model, i.e., relation between a damage state/failure mode and the corresponding damage degree [62].

The consequence assessment could be performed for each asset individually or on a portfolio of assets. Assessment at the level of the individual assets is challenging as it requires development of a series of structural vulnerability functions as well as access to detailed data about the assets. Thus, for regional scale analyses, it is proposed to work on the portfolio level, classifying the assets into homogeneous classes. The idea is to identify the key parameters for a group of assets, which can be readily applied in development of the series of fragility functions. For example, to cluster similar bridges, features that govern the resistance to extreme events are identified. Such features might be intrinsic such as bridge material, mileage, or span count, or extrinsic such as local weather conditions or traffic. Further steps in the portfolio assessment encompass estimation of number of assets within each class in the study area and relating the failure mode to an intensity parameter of a hazard process. The total direct consequences are found by an aggregation of the monetized structural damage to all the assets in the flooded area $[27,56,63]$.

In the evaluation of direct consequences to infrastructure due to natural hazards, some simplifications can be adopted. For example, drainage systems and roads are usually designed based on a specific return period of flooding or rainfall. In these and similar cases, it is a valid assumption to adopt neglectable damages for flooding events with return periods below the design rainfall/flooding event. Such approximation is demonstrated in Section 3.3.

\subsubsection{Assessment of Indirect Consequences}

In estimation of indirect consequences of extreme events on transportation systems, assessment of disruption of the related transportation service(s) is the key task. For such assessments, functional vulnerability functions are useful, expressing directly the probability of service disruption as a function of event intensity instead of probability of structural damage states [2,40]. Functional vulnerability functions are feasible for quantitative vulnerability assessment at a network level, describing the functionality loss (e.g., reduction of a traffic capacity) due to a given hazard intensity.

A service disruption would leave the travelers with several options: postpone or cancel the trip, change mode of transport or travel destination, or take a detour [64]. The severity of the indirect consequences is influenced by the failure mode (e.g., full/partial closure), the duration of the service disruption, the quality and capacity of the alternative transportation routes or alternative modes of transportation as well as the traffic volume and traffic composition in the affected network. The main portion of indirect costs to users stems from additional travel time, which is commonly used in calculations (e.g., the total time delay in [65]). Besides additional travel time, if sufficient input data on traffic are available, other consequences can be included as well: those due to the increased travel distances (via fuel consumption) and accident costs (e.g., [66]), increased air pollution and increased noise [67]. Further, indirect consequences can also encompass costs related to work time lost, and loss of income due to perishable goods spoiling. Long-term indirect effects of a repeatedly malfunctioning infrastructure could also comprise change in travel patterns affection, e.g., tourism and businesses depending on the transportation line. 
Meyer et al. [19] gave a broad review of assessment of indirect costs of natural hazards affecting infrastructure. The review encompasses methods such as event analysis, econometric approaches, input-output analysis, computable general equilibrium analysis, intermediate models, public finance analysis and idealized models.

Network analysis is used to determine the flow of vehicles through a transport network. Network analysis could be based on:

- Graph theory and topological properties of the transport network. Such approaches consider networks as a collection of vertices (or nodes) that are connected by arcs (or links) and consider the importance of different links, cascading failures and interdependencies between different networks. Graph-theoretical concepts are useful for the description of transport network characteristics and its connectivity [18].

- Understanding of the dynamic behavior exhibited on networks (e.g., traffic flow) using transportation system models, modelling demand and supply side of the transport system and travelers' responses to disturbances and disruptions. Most risk frameworks account for traffic-related consequences using a macroscopic model with static user-equilibrium flow formulation. This traffic assignment model presents strong assumptions such as steady traffic conditions during the time of investigation, constant demand, and user's complete knowledge of the traffic conditions. The traffic flow could be modelled, e.g., considering the traffic as a fluid and using models based on fluid dynamics equations [68]. However, it has been found that traffic demands and changes in travel patterns, i.e., in destination and mode choice, may be significantly altered after the occurrence of hazardous events [4]. Users' response represents the main capability of the system to adapt to changes when any disruptive event occurs. Recent research has investigated the stochastic user's behavior in disrupted networks to provide a more realistic mobility pattern [69].

The modelling could encompass behavioral responses of the travelers to network disruptions or other changes in the supply side of the transport system. The travelers' behavior would affect the demand side of the transport system. Important mathematical and statistical aspects of the disposition and behavior of road traffic are considered by [70].

The failure modes provided in Table 1, involve a different course of events from a malfunctioning of infrastructure back to its normal operation and result in different durations of service disruptions. It should be noted that resourcefulness (i.e., availability of adequate human, machinery, funding resources) and duration of procedures preceding the restoration activities (elaborating project documentation, tenders) can also impact the duration of service disruption.

Failure modes involving structural damage and functional failure of assets can be related from a short (hours/days) to a long duration (months/years), depending on the extent and complexity of repair/restoration activities (or a replacement of failed assets). The same goes for failure modes involving failure of supporting systems (e.g., gas, electricity). The severity of service disruption caused by material or debris on the transportation line would depend on volume of material on the roadway/track to be removed and available resources to act on a short notice. For the failure modes involving dangerous driving conditions and precautionary closure due to exceedance of a weather parameter threshold, these solely depend on natural conditions and generally relate to a short duration (e.g., hours) of service disruption. A simplified way to calculate the indirect consequences is presented in Equation (6).

$$
C_{\text {indirect }}(F M)=C S \cdot D(F M)
$$

\subsection{Proposed Framework for Risk Assessment of Terrestrial Transportation Systems}

Following the risk assessment steps and the conceptualization in Sections 2.2-2.4, the risk assessment encompasses identification of risk scenarios and selection of analysis scope (FM and extreme event $E E)$, assessment of hazard $\left(P_{\text {temporal }}\left(E E_{i}\right)\right)$, exposure (assets where $i>1)$, vulnerability $(P(F M \mid E E i)$ and structural damage, $S D)$ and consequences $(C(F M))$. 
These steps are illustrated in Figure 2. The risk associated with one failure mode, $R(F M)$, could be expressed as:

$$
R(F M)=P_{\text {temporal }}(F M) \cdot \mathrm{C}(F M)
$$

The steps necessary for assessment of risk posed by natural and human-made hazard events on transportation systems are illustrated in Figure 2.

It is worth noting that the implementation of the proposed framework is based upon the assumption that an inventory of the infrastructure assets is provided by the infrastructure owner. However, the unavailability of high-quality inventory data is an issue shared by many countries. One of the main drivers of this problem is the lack of a systematic data collection procedure. Thus, some efforts have been made to propose protocolled taxonomy and methods for data collection, aiming at unifying databases into a functional structure ready to be used in risk assessment frameworks (e.g., [21,22]).

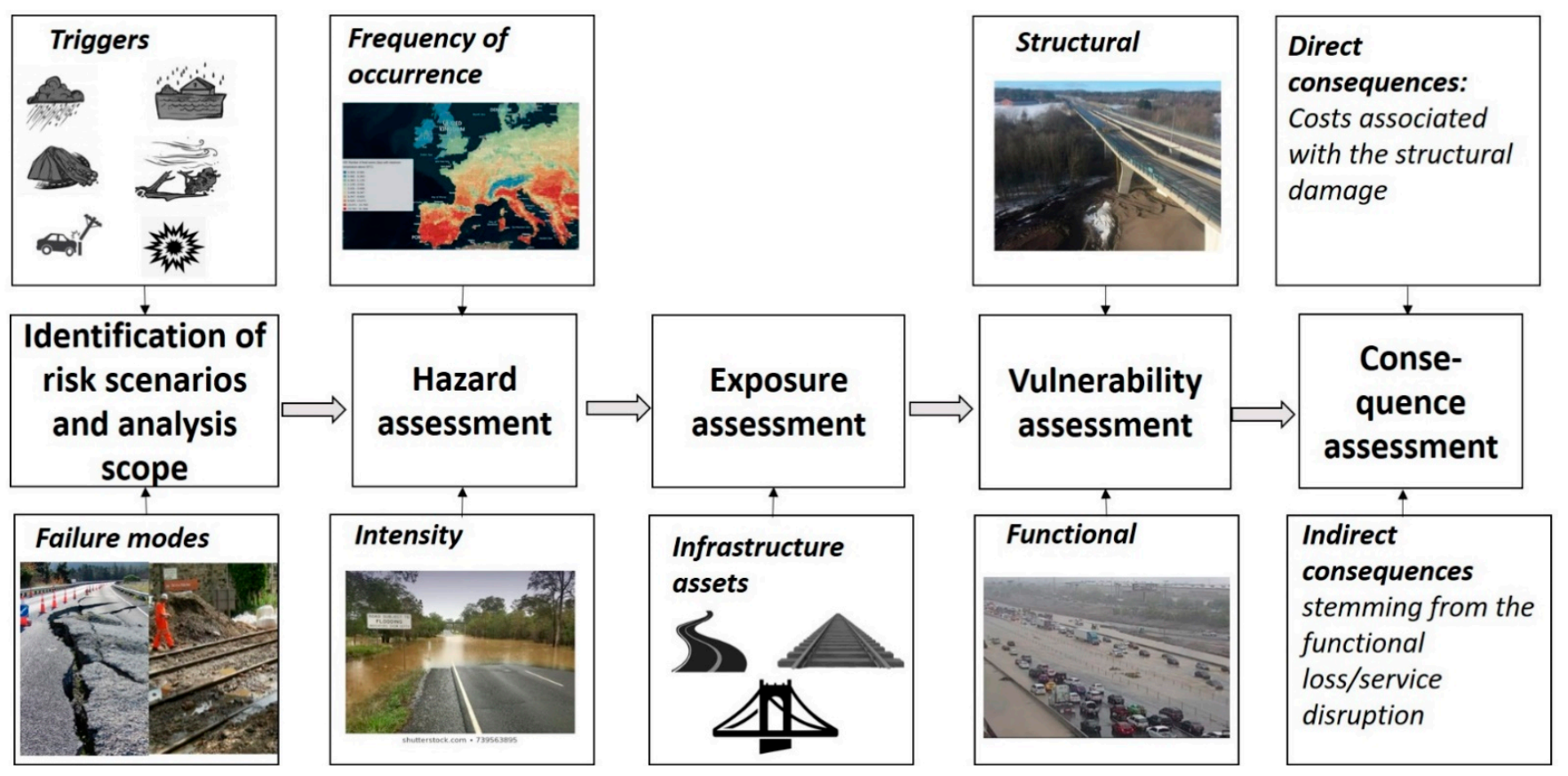

Figure 2. Framework for assessment of risk associated with extreme events on transportation systems.

\section{Application Examples}

The next subsections provide examples of assessment of hazard, vulnerability and risk. The hazard assessment examples (Section 3.1) demonstrate assessment of the temporal probabilities from Equation (1)

- $\quad P_{\text {temporal }}(F M)$, for the failure mode failure of bridge caused by human-made hazard (Section 3.1.1);

- $\quad P_{\text {temporal }}\left(E E_{i}\right)$, for the extreme event flooding, for a range of flooding intensities $i$ (Section 3.1.2);

- $\quad P_{\text {temporal }}\left(E E_{i}\right)$ of natural hazards from available data bases and data sources (Section 3.1.3).

Addressing the lack of vulnerability functions, a vulnerability assessment example is provided, demonstrating the development of a fragility curve for the failure mode bridge failure caused by flooding-induced bridge scour. The fragility curve expresses $P\left(F M \mid E E_{i}\right)$ for a range of flooding intensities (Section 3.2).

The risk assessment example demonstrates the assessment of $R(F M)$ for the failure mode service disruption of road caused by flooding and exceeded culvert capacity (Section 3.3). 


\subsection{Hazard Assessment Examples}

\subsubsection{Use of Bridge Failure Data for a Temporal Probability Assessment}

Table 4 describes the rate of failure of existing bridges from 1966 to 2020 based on a worldwide bridge failure database [71]. The content of this table is limited to existing bridges, therefore disregarding failure during the construction phase. Accordingly, the main causes of failure were grouped in two main groups (Figure 3), natural hazards (NHs) and artificial hazards. This last one has been subdivided into three subgroups, namely, human-made hazards (HMHs), human error (i.e., design and construction errors (D\&CEs) and operational errors (OEs)). A more detailed discussion on the proposed classification concerning the causes of failure can be found in [72].

Table 4. Rate of failure of existing bridges (data extracted from: [71]).

\begin{tabular}{|c|c|c|c|c|c|c|}
\hline \multirow{2}{*}{ Period } & \multirow{2}{*}{$\begin{array}{c}\text { Recorded } \\
\text { Failures }\end{array}$} & \multirow{2}{*}{ Percentage } & \multicolumn{4}{|c|}{ Failure Frequency * } \\
\hline & & & NHs & HMHs & D \& CEs & OEs \\
\hline $1966-1970$ & 10 & $1.5 \%$ & & & & \\
\hline 1971-1975 & 18 & $2.7 \%$ & & & & \\
\hline 1976-1980 & 38 & $5.8 \%$ & & & & \\
\hline 1981-1985 & 13 & $2.0 \%$ & & & & \\
\hline 1986-1990 & 20 & $3.0 \%$ & & & & \\
\hline 1991-1995 & 16 & $2.4 \%$ & & & & \\
\hline 1996-2000 & 21 & $3.2 \%$ & & & & \\
\hline $2001-2005$ & 65 & $9.9 \%$ & & & & \\
\hline 2006-2010 & 108 & $16.4 \%$ & & & & \\
\hline 2011-2015 & 157 & $23.9 \%$ & & & & \\
\hline $2016-2020$ & 191 & $29.1 \%$ & $1.92 \times 10^{-5}$ & $1.86 \times 10^{-5}$ & $2.79 \times 10^{-6}$ & $1.40 \times 10^{-5}$ \\
\hline Total & 657 & $100 \% * *$ & & & & \\
\hline \multicolumn{7}{|c|}{ Total Bridge Stock: 3.225.047 [73] } \\
\hline
\end{tabular}

* NH: natural hazards; HMH: human-made hazards; D\&CE: design and construction errors; OE: operational errors. ${ }^{* *}$ Due to rounding error, the sum of the percentages shown in the table is not exactly $100 \%$.

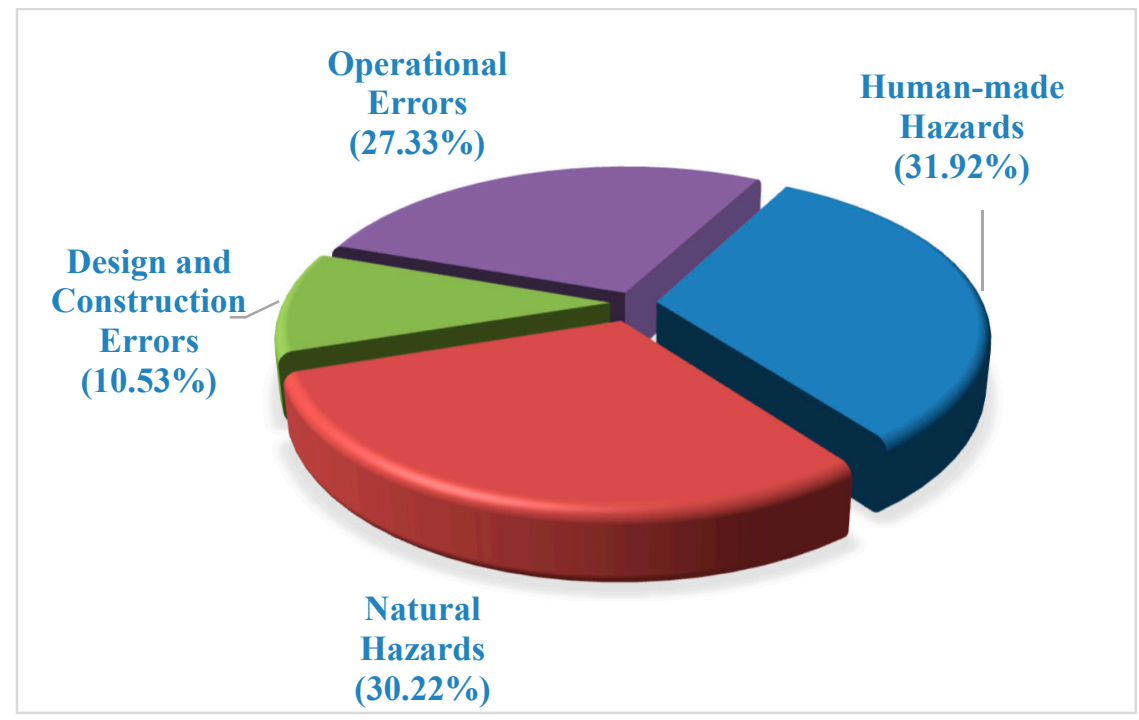

Figure 3. Main causes of failure of existing bridges (1966-2020).

By tracking the recorded number of failures since 1966, an increasing trend is observed. Although the causes behind this trend are unknown, one can speculate that information from more recent failures is easier to obtain, e.g., through social media. Nonetheless, the ageing of the bridge stock, increasing traffic load, climate change and the growth of the built environment, as society evolves, are also variables that must be considered. 
The total number of bridge stock around the globe is roughly estimated to be 3,225,047 according to [73]. Using such number and according to the number of failures recorded between 2016 and 2020 and the main cause of failure, the failure frequency for each main cause is estimated. NHs and HMHs are the main causes of failure. The total frequency of failure is estimated to be around $5.46 \times 10^{-5}$ for a five-year period, which corresponds to an average annual failure frequency around $1.09 \times 10^{-5}$. Similar numbers were presented in [73] for some bridge failure databases analyzed under the scope of the developed work. Curiously, the annual target failure probability for ultimate limit state proposed in [74] is $1.0 \times 10^{-6}(\beta=4.7)$ for a structure of reliability class two (RC2). Nevertheless, when factoring the cost of safety and consequence of failure, considering normal cost of safety and moderate consequences (something expected from typical bridges according to ISO 2394:2015), an annual target probability of failure around $1.0 \times 10^{-5}(\beta=4.2)$ is suggested [75].

The average annual bridge-failure probability due human-made hazards is in the same way estimated as $3.72 \times 10^{-6}$. This number represents mostly the failure of bridges triggered by unintentional human-made hazards (ship and vehicle collisions, and overloading caused by users).

\subsubsection{Flood Hazard Assessment on a Local Level}

One of the most widespread approaches for assessing the flood hazard consists of estimating the extreme discharge for a given exceedance probability by fitting of a probability distribution function to a record of annual maximum discharges. This method, frequently referred to as flood frequency analysis (FFA), has been standardized in different manuals such as in the Flood Estimation Handbook in the UK [76] and the Bulletin 17C in the US [77].

A flood frequency curve was derived for the Tagus River in Portugal at Tramagal river gauge location. Data are available for 26 years of records approximately.

Despite that there is no standardization proposed at the Portuguese level, a Gumbel distribution is assumed to represent more appropriately the peak discharges as suggested by the Management Plan of the Tagus Hydrographic Region [78]. The L-moments method was used to estimate the parameters of the Gumbel distribution. Gumbel probability plots and Chi-squared goodness of fit tests showed that the peak annual discharge can be reasonably well modelled by a Gumbel probability distribution function (see Figure 4).

It is acknowledged that the obtained flood frequency curve is not an exact approximation, as the record of annual peak flows at a given location is a random sample of the underlying population of annual peaks. Then, to quantify the confidence of this approximation, an interval which contains the population frequency curve is commonly constructed (usually 95\% of confidence is used) [77]. In this manner, the uncertainty in the flood event intensity due to sampling variability is considered, yet conditional on the choice of a particular distribution.

It can be observed from Figure 4 that for smaller, i.e., more frequent events, the reliability of the discharge estimation is greater than for larger events (very wide confidence intervals). This is expected as the database of past events is sparse, i.e., only 25 years of records are available. Thus, there are significant uncertainties in the estimated river discharges obtained through this statistical approach. As more data become available, it is expected that the estimates improve and consequently the confidence intervals narrowed.

Despite the wide applicability of the method, it should be kept in mind that the accuracy of the estimated flood frequency curve depends on many factors, such as the records sample size, its representativeness, errors in the measured annual peak discharges and the underlined assumptions, namely the appropriateness of the chosen distribution and the hydrologic stationarity $[77,79]$. Research efforts are being conducted with the overall aim of reducing all these sources of epistemic and aleatory uncertainties in the estimation of flood frequency analysis. 


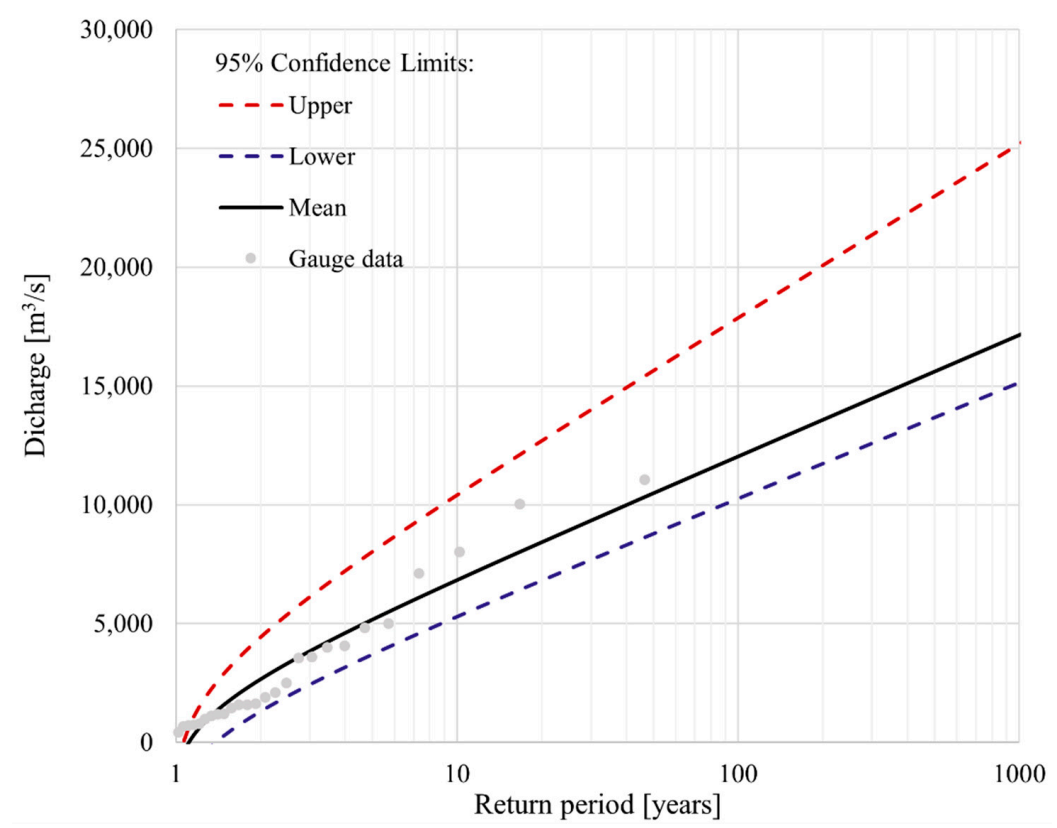

Figure 4. Flood frequency curve for the Tagus River at Tramagal river gauge.

Figure 4 expresses the relationship between return period of flooding and flooding intensity (i.e., discharge). To assess the temporal probability of flooding, equation 8 could be applied, where the discharge represents the intensity $i$.

$$
P_{\text {temporal }}\left(E E_{i}\right)=\frac{1}{\text { Return period for } i}
$$

\subsubsection{Natural Hazards at Regional Level}

$P\left(E E_{i}\right)$ may also be found from already existing hazard data. Freely available data sources on natural hazards at the European level compatible with GIS include: flood hazard maps and catalogues, wildfire catalogues, hazard maps related to wind and temperature (heat), landslide hazard maps, earthquake hazard maps and catalogues and rainfall catalogue and forecast analyses. An overview of available inventories, databases and GIS maps of natural hazards at the European level is provided by [80].

Hazard maps for natural events may represent past, current or future hazard situations, where the latter typically would account for climate changes. For projections of future hazard situations or assessment of changes in the hazard situation due to climate change, a time span and representative concentration pathway need to be selected. An overview of effect of climate change on a variety of natural hazards for different time spans and emission scenarios is provided by [11].

\subsection{Vulnerability Assessment Example of an Asset-Specific Assessment of a Fragility Curve-A Case of a Bridge Scour in Portugal}

In most approaches found in the literature, failure of bridges on shallow foundations is assumed to occur when the predicted local scour depth reaches the foundation base, which has been demonstrated to be a conservative assumption for multiple span RC girder bridges [37] as well as for masonry arch bridges [81]. Consequently, it is important to identify the maximum scour depth and extent (i.e., the geometry of the scour cavity) beneath the foundation level that the soil-bridge structure may withstand before collapse [81,82]).

Masonry arch bridges (MAB) have been recognized as particularly vulnerable to local scour due to their rigid behavior and the fact they are often built on shallow footings [83]. In this respect, a fragility analysis of a four-span masonry arch bridge under flood-induced scour was conducted (Figure 5). The bridge considered is located at the Santarém district, Portugal, and presents a total length of approximately $30 \mathrm{~m}$, with arch spans of $4.80 \mathrm{~m}$. The 
bridge piers are wall-type sections $(1.0 \times 7.0 \mathrm{~m})$ with round-nose shape and $1.85 \mathrm{~m}$ height. The pier footings are $1.20 \mathrm{~m}$ thick, and $2.55 \mathrm{~m}$ length. The foundation soil corresponds to an alluvial deposit that is mostly granular, with coarse sands loosely cohesive, which renders the bridge susceptible to scour.

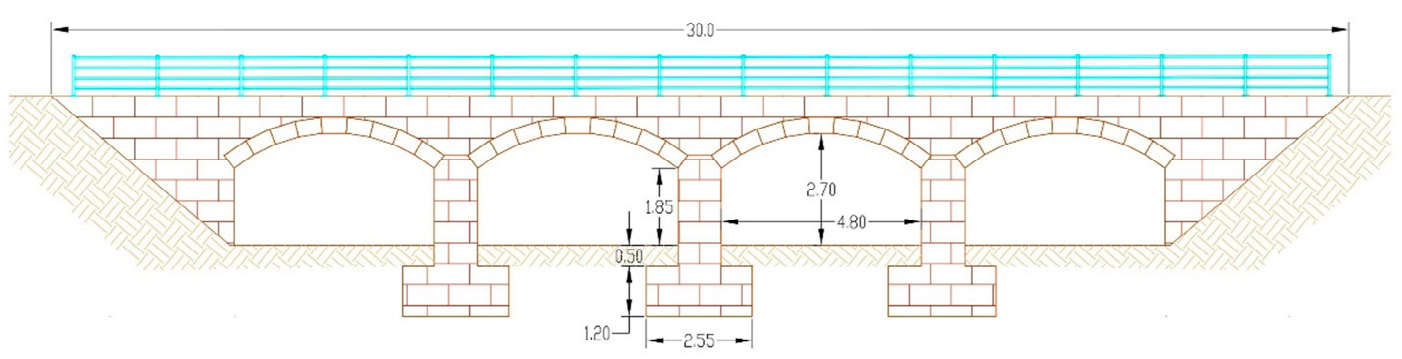

Figure 5. Masonry arch bridge under study (dimensions in meters).

Based on the shape of the local scour cavity at the foundation, MAB can exhibit different failure modes such as fragmentation of piers/abutments, out-of-plane failures, and symmetrical or non-symmetrical in-plane failures [46]. Due to the squat piers in the transversal direction to the flow, an out-of-plane failure mechanism is not expected. Conversely, depending on the inclination of the water flow, a symmetrical or non-symmetrical in-plane failure mechanism can develop. It is assumed for the MAB under analysis that the water flow is aligned to the piers and that the scour is acting at the base of the central pier, while the other piers did not significantly experience this phenomenon.

All random variables associated with the soil-bridge resistance, load effects, and model uncertainties were considered in the analysis. The probability density function (PDF) of peak flow discharges for the waterway where the bridge is located is estimated from flow regionalization curves provided by the Management Plan of the Tagus Hydrographic Region [78]. Since there are no available data to estimate flood hydrographs, a peak flood duration of $48 \mathrm{~h}$ is assumed. The Gauckler-Manning-Strickler formula is considered for the hydraulic analysis under the assumption of uniform flow conditions. Probability distributions for the hydraulic parameters, i.e., Manning roughness coefficient and channel slope, are adopted from [84] (Table 5). Based on the hydraulic loads and the soil characteristics on the site, local scour at a bridge pier was investigated as the most probable cause of a failure in a flooding event.

Table 5. Statistical properties of variables.

\begin{tabular}{|c|c|c|c|c|c|}
\hline \multicolumn{2}{|r|}{ Parameters } & Mean ${ }^{1}$ [Units] & $\mathrm{COV}$ & Distribution & Reference $^{2}$ \\
\hline \multirow{7}{*}{$\begin{array}{l}\text { Local scour } \\
\text { action }\end{array}$} & Peak discharge & $74.6\left[\mathrm{~m}^{3} / \mathrm{s}\right]$ & 0.70 & Gumbel & [78] \\
\hline & Peak flood duration & $48[\mathrm{~h}]$ & - & - & Assumed \\
\hline & Channel width & $30[\mathrm{~m}]$ & 0.05 & Normal & Assumed \\
\hline & Channel bed slope & $0.002[\mathrm{~m} / \mathrm{m}]$ & 0.10 & Normal & Assumed \\
\hline & Manning roughness coefficient & $0.035\left[\mathrm{~s} / \mathrm{m}^{1 / 3}\right]$ & 0.015 & Lognormal & [84] \\
\hline & Riverbed mean size diameter & $20[\mathrm{~mm}]$ & 0.1 & Lognormal & Assumed \\
\hline & Scour model error & 0.80 & 0.20 & Normal & [84] \\
\hline \multirow{2}{*}{ Soil properties } & Angle of friction & $35\left[^{\circ}\right]$ & 0.05 & Normal & [85] \\
\hline & Saturated unit weight & $19\left[\mathrm{kN} / \mathrm{m}^{3}\right]$ & 0.05 & Normal & [75] \\
\hline \multirow{7}{*}{ Bridge properties } & Pier width & $1.0[\mathrm{~m}]$ & - & - & Assumed \\
\hline & Masonry unit weight & $25\left[\mathrm{kN} / \mathrm{m}^{3}\right]$ & 0.05 & Normal & [75] \\
\hline & Masonry compressive strength & $3000\left[\mathrm{kN} / \mathrm{m}^{2}\right]$ & 0.15 & Normal & [86] \\
\hline & Masonry joints friction coefficient & 0.60 & 0.15 & Normal & [86] \\
\hline & Backfill angle of friction & $35\left[^{\circ}\right]$ & 0.10 & Normal & [86] \\
\hline & Backfill cohesion & $30\left[\mathrm{kN} / \mathrm{m}^{2}\right]$ & 0.15 & Normal & [86] \\
\hline & Backfill unit weight & $17\left[\mathrm{kN} / \mathrm{m}^{3}\right]$ & 0.05 & Normal & [75] \\
\hline \multicolumn{2}{|c|}{ Computational model uncertainty factor } & 1.0 & 0.15 & Normal & [75] \\
\hline
\end{tabular}

\footnotetext{
${ }^{1}$ Assumed except as otherwise indicated. ${ }^{2}$ Regarding to the COV value and the distribution type selection.
} 
The local scour depth was estimated following the FDOT methodology with the Melville-Sheppard (M-S) equation to account for the temporal scour evolution [87]. The epistemic uncertainty associated with the accuracy of the FDOT method to predict scour has been considered through the application of a normally distributed model error with mean value equal to a bias factor and a coefficient of variation (COV) (Table 5), obtained from the ratio of observed scour with predicted scour as suggested by [84].

Discontinuity layout optimization (DLO), which is a numerical limit analysis technique, is used herein to estimate the collapse load of the structure [88]. Masonry units were modelled using a rigid material model, and masonry joints were modelled using a Mohr-Coulomb model with zero cohesion and an angle of friction derived from the coefficient of friction. A Mohr-Coulomb model was also considered for the backfill and the foundation soil, as well as for interface elements used to model the interface between the bridge elements and the soil. All material properties used in the analysis together with the probability distributions selected to describe each variable are shown in Table 5. Masonry units were modelled using a rigid material model, and masonry joints were modelled using a Mohr-Coulomb model with zero cohesion and an angle of friction derived from the coefficient of friction. A Mohr-Coulomb model was also considered for the backfill and the foundation soil, as well as for interface elements used to model the interface between the bridge elements and the soil. The material properties used in the analysis, i.e., masonry compressive strength, unit weights for each material, and internal friction angles, together with the probability distributions selected to describe each variable, are shown in Table 5.

The scour effect was modelled by the removal of soil around and under the foundation, assuming that the scour cavity slope along the direction perpendicular to the flow is equal to $5 / 6 \cdot \phi$ (soil friction angle,) as proposed by [83]. Figure 6 shows the masonry arch bridge modelled in LimitState:GEO [89] for the no-scour condition (Figure 6a) and for different scour depth configurations, i.e., $1.30 \mathrm{~m}$ of scour depth (Figure $6 \mathrm{~b}$ ), and $1.85 \mathrm{~m}$ of scour depth leading to soil underneath the pier foundation being eroded (Figure $6 \mathrm{c}$ ). It should be noted that a symmetrical in-plane failure mode was assumed, as the water flow is aligned with respect to the pier plan orientation (if skewed, the expected failure mode would be non-symmetrical).

The flood discharge, $Q$, was considered as the intensity measure for the fragility functions. An adequacy factor, which is defined as the factor by which specified loads must be increased in order for the system to reach a collapse state, was obtained in LimitState:GEO by modelling the corresponding loading conditions, i.e., the scour cavity and hydrodynamic pressure for different Qs, namely discharges associated to 5-, 20-, 50-, 100-, 500- and 1000-year floods. The collapse load factors from 150 DLO models generated through Latin Hypercube Sampling were used to define the soil-bridge resistance distribution, $R$. The load distribution, $\mathrm{S}$, was defined by a curve with a mean value equal to one and a standard deviation of 0.05 since the resistance is quantified as a function of the self-weight [75]. The limit state equation is then defined as $G=R-S=0$, where the failure of the system takes place for $\mathrm{R}<\mathrm{S}$ or $\mathrm{G}<0$ [72]. Subsequently, the reliability analysis was performed for each $\mathrm{Q}$ using the first-order reliability method (FORM). Finally, the estimation of the parameters of the fragility curve was achieved by performing a generalized linear model (GLM) regression over the set of data points at the selected Qs, to describe the fragility function as a lognormal probability distribution function [90].

The fragility analysis was performed for two different scenarios, one assuming that the equilibrium scour depth is attained for the given discharge and the other considering a time-dependent scour depth given a flood duration of $48 \mathrm{~h}$. The obtained fragility curves are shown in Figure 7. For the former case, the probability of bridge scour leading to failure given a flooding with discharge $300 \mathrm{~m}^{3} / \mathrm{s}$, i.e., $P\left(F M \mid Q=300 \mathrm{~m}^{3} / \mathrm{s}\right)$, is equal to 0.043 , while for the latter case it corresponds to 0.017 . These results highlight that the assumption of attainment of the equilibrium scour which is often made for assessing bridge vulnerability may be overconservative. Thus, it is important to investigate the event durations within 
scour fragility analysis. The bridge functionality associated to the damage levels that were analyzed corresponds to $100 \%$ loss of service.

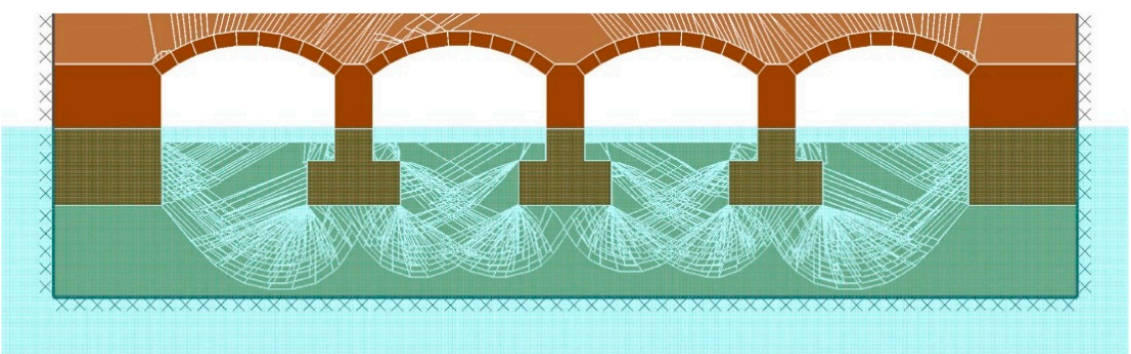

(a)

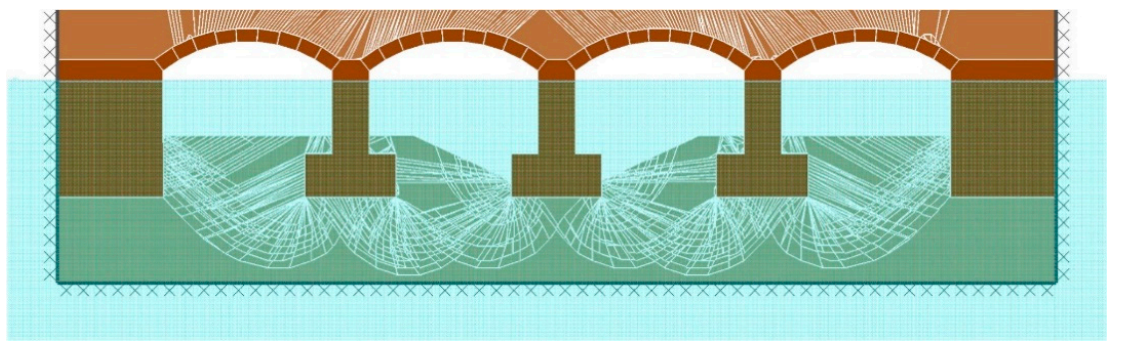

(b)

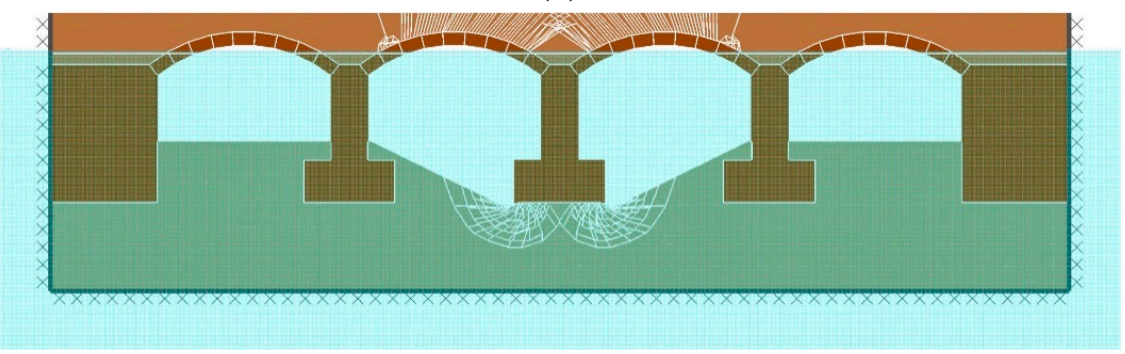

(c)

Figure 6. DLO model of the masonry arch bridge in LimitState:GEO [89]: (a) no scour condition, (b) $1.30 \mathrm{~m}$ of scour depth, (c) $1.85 \mathrm{~m}$ of scour depth.

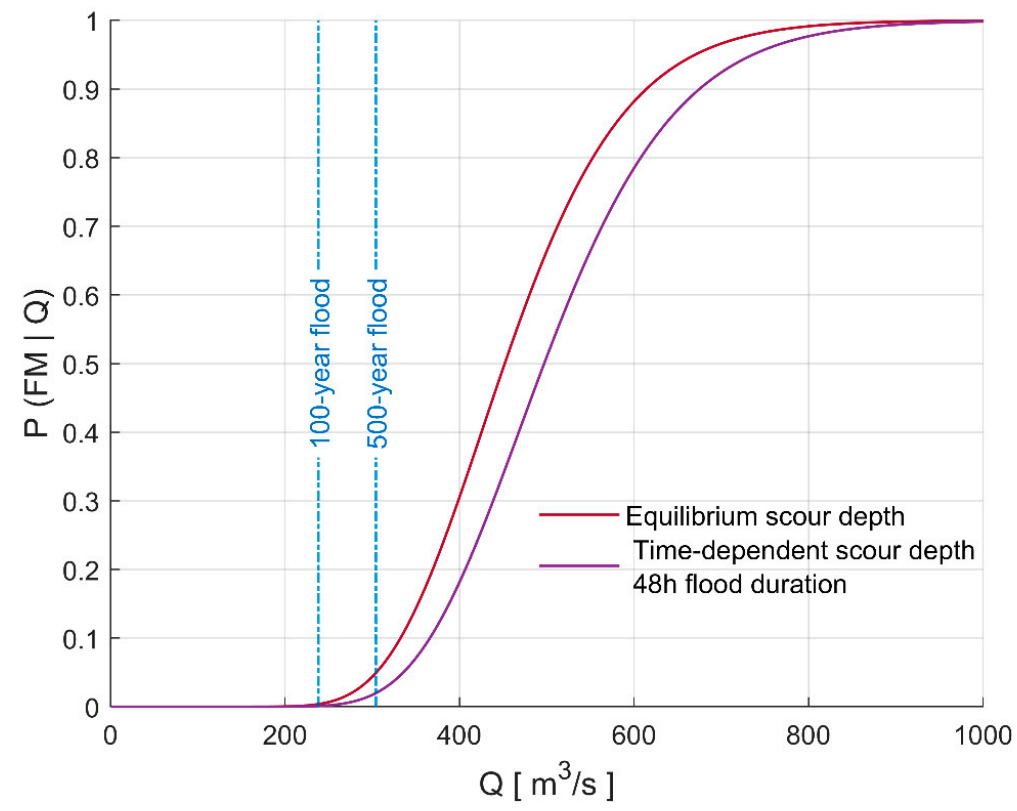

Figure 7. Flood fragility function for the MAB under study. 


\subsection{Risk Assessment Example: Asset Failure and Related Service Disruption}

This section demonstrates assessment of service disruption caused by a structural asset failure for a generic road link, considering flooding of roadway due to exceeded culvert capacity. The context of this analysis could be that the analyzed road link is of high importance for the road network and that the culvert considered is the most critical asset at this road link. The assessment is done following the steps of the risk assessment framework (Figure 2). An overview of data and models needed for the assessment is given in Table 6.

Table 6. Data and models needed for the assessment.

\section{Step in Risk Framework}

Identification of risk scenarios

Hazard assessment

Exposure

Vulnerability

Consequence
Data, Models and Considerations Necessary for Defining Events and Assessment of Event Probabilities

Selection of analysis object, hazard type and failure modes for this case: The analysis object (asset) is a road link over a culvert, and the hazard to be considered is flooding. The failure modes encompass flooding of roadway leading to different degrees of capacity reductions (from insignificant reductions to full closure). Exceedance of culvert capacity and structural damage to the roadway are also considered as part of the assessment.

Data needed for assessment of $P_{\text {temporal }}\left(E E_{i}\right)$ : flood hazard maps for selected return periods, showing water depth and velocity, i.e., flood intensity values to be applied in the vulnerability assessment. Data needed: flood hazard maps and maps of the road. The road link in study is assumed to be in a flood-prone area.

Tool for assessment of $P\left(F M \mid E E_{i}\right)$ :

FM: service disruption of the road: functional vulnerability providing vehicle speed as a function of flood depth of road, adopted from [5].

FM: structural damage of roadway: structural vulnerability relations for roadway/pavement exposed to flooding [56].

This example encompasses failure modes represented by several sequences of events leading to different consequences. The severity of the consequences is determined by the degree of capacity reductions (e.g., if the road is only partly closed or the traffic is possible with reduced speed) and the duration of the service disruption. Four consequence severity classes are adopted (Table 7). Only capacity reduction below the demand will represent a failure mode. The demand expresses the transport needs, usually expressed in AADT (annual average daily traffic).

Table 7. Adopted consequence severity classes.

\begin{tabular}{cc}
\hline $\begin{array}{c}\text { Consequence } \\
\text { Severity Class }\end{array}$ & Description \\
\hline Very high & Closed road for long duration (weeks-months) \\
High & Closed road for days or severe capacity reduction for weeks \\
Moderate & Moderate capacity reductions with limited durations (hours-days) \\
Low & Insignificant delays or capacity reduction with duration less than a few hours \\
\hline
\end{tabular}

The assessment is conducted by use of Event Tree Analysis [91]. Event tree analysis (ETA) is a logical modelling technique that shows all possible outcomes resulting from an initiating event, considering further events and factors that affect the performance of the system, e.g., whether installed safety barriers are functioning or not. The analysis considers the sequence of events that could lead to failure by asking "what can happen if?" at every step. ETA may be used for assessing hazard and consequences, assessing probabilities of the outcomes and overall system analysis. It is applicable for qualitative as well as quantitative assessment.

The steps considered in ETA are as follows (if a flooding event occurs):

- What is the return period of the flooding event that may pose a threat?

- Is the culvert capacity exceeded?

- Will flooding of the road cause full service disruption?

- Will flooding cause material damage?

- Is the capacity reduced below demand? 
- How severe are the consequences?

Figure 8 illustrates the event tree constructed from the assessment steps above as well as event probabilities (at the branch prior to an event). Each sequence of events will lead to a different consequence in terms of severity and duration of service disruption. The probability of each sequence of events is found by multiplying the probabilities along the branch. The value is shown next to the consequence severity class. The following simplifications are made when assessing the severity of the consequences:

- Very high consequences: A flood depth higher than $30 \mathrm{~cm}$, velocity of the flooding water high enough to cause material damage to the roadway.

- High consequences: A flood depth higher than $30 \mathrm{~cm}$, velocity of the flooding water not high enough to cause material damage to the roadway.

- Moderate consequences: A flood depth less than $30 \mathrm{~cm}$. The capacity of the roadway is reduced to less than the demand.

- Low consequences: A flood depth less than $30 \mathrm{~cm}$. The capacity of the roadway is larger than the demand (including the case where the culvert capacity is not exceeded).

Table 8 indicates which considerations should be done and the reasoning behind the choice of event probabilities in Figure 8.

Table 8. Definition of events and considerations for assessment of event probabilities.

Assessment Steps

What is the return period of the flooding event?

Is the culvert capacity exceeded?

Does the flooding cause full service disruption? (Is the

flood depth at the roadway above a threshold for full service disruption?)

Does the flooding cause material damage? (Is the intensity of the flooding high enough to cause material damage?)

Is the capacity reduced below demand?

What are the consequences?
Example of Assessment (Explanation of the Choice of Probabilities in the Event Tree in Figure 8)

The event tree in Figure 8 is for the 60-300-year flooding event (represented by/applying data for the 200-year flooding event, Table 9).

$$
\mathrm{p}=1 / 60 \mathrm{yr}-1 / 300 \mathrm{yr}=0.013 / \mathrm{yr}
$$

The culvert is designed for the 200-year flood, but we assume there is a long time since the last inspection and the capacity may have been reduced due to debris deposition, $\mathrm{P}$ (exceeded culvert capacity) $=0.5$.

A threshold of $30 \mathrm{~cm}$ is chosen in accordance with the curve from [5], corresponding to full service disruption.

Probability of a flood depth larger than $30 \mathrm{~cm}$ could be estimated considering different degrees of culvert capacity reduction. We assume that the critical level of clogging for the circumstances considered in this case occurs in $20 \%$ of the cases, i.e., $\mathrm{P}($ flood depth $>30 \mathrm{~cm})=0.2$.

The intensity of the flooding is compared to flood intensity thresholds for structural damage from [56]. We assume that the flooding intensity is close to the threshold and consequently that $\mathrm{P}$ (flood intensity $\geq$ threshold) $=0.5$.

We assume that application of the functional vulnerability model from [5] indicates that the probability of reducing the capacity below demand is $60 \%$ for flood depths below $30 \mathrm{~cm}$.

Dependent on the sequence of events, the consequences could be very high, high, moderate or low. The probability of one consequence severity class encompasses the probabilities of all sequences of events leading to that consequence class.

Table 9. Return period classes and flood scenarios used in the assessment.

\begin{tabular}{cc}
\hline Return Period Range & $\begin{array}{c}\text { Representative Flood Scenario Used in } \\
\text { Analyses }\end{array}$ \\
\hline$<10$ years & No loss \\
$10-60$ years & 50 -year \\
$>60-300$ years & 200 -year \\
$>300$ years & 500 -year \\
\hline
\end{tabular}




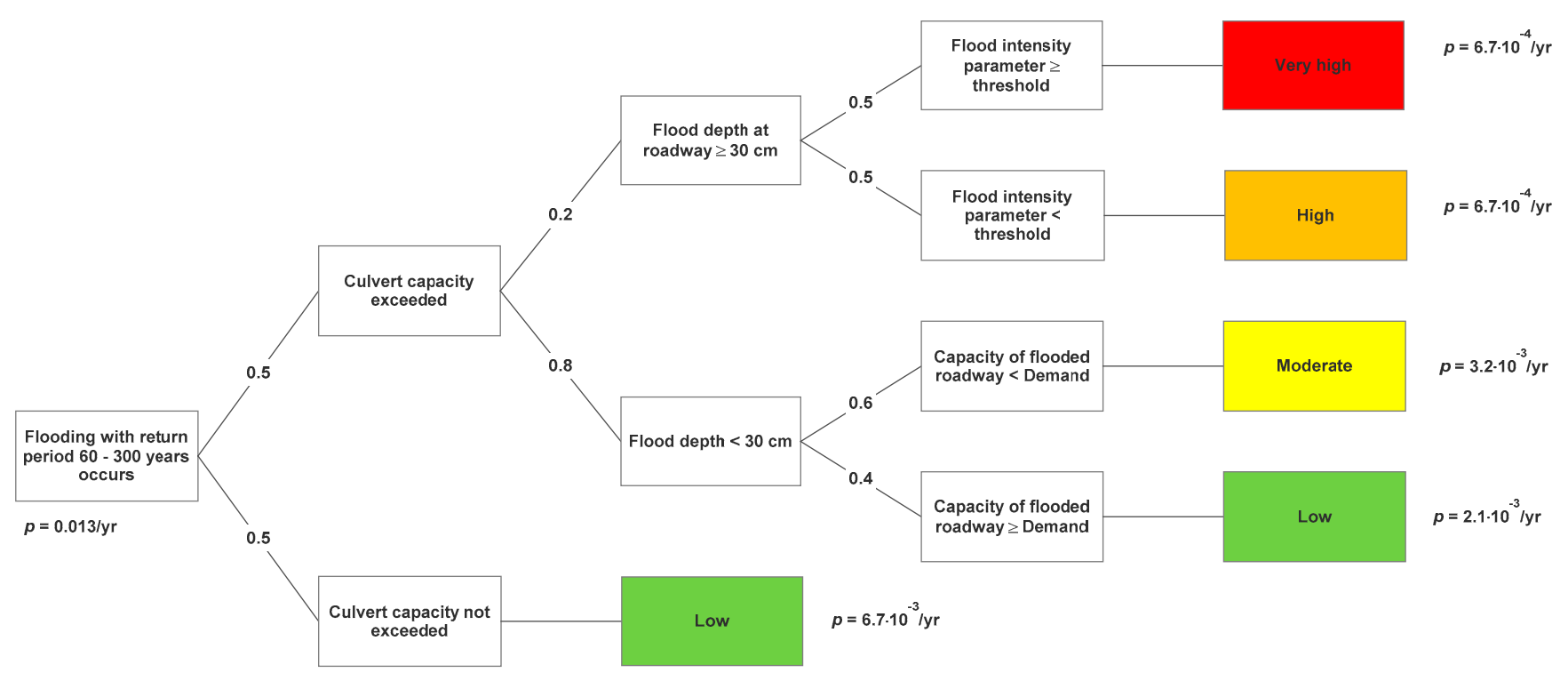

Figure 8. Quantitative assessment of the probability for different consequence classes.

In accordance with Equation (1), the full range of plausible intensities of $E E_{i}$ should be accounted for and their contributions summed. Table 9 outlines four different flood scenarios to be applied in the assessment, as well as the range of probabilities covered by each scenario.

Figure 8 demonstrates the assessment for the 200-year flood scenario (representing return periods of 60-300 years as indicated in Table 9). The structure in Figure 8 is applied for assessments of the scenarios representing return periods $<60$ years and higher than 300 years, but with different event probabilities. The summation of the contribution from each of the return period ranges is presented in Table 10. The result of the assessment is that the annual probability is 0.987 for low consequences, $8.1 \cdot 10^{-3}$ for moderate consequences and $2.3 \cdot 10^{-3}$ for high consequences and for very high consequences. The risk can be further quantified by calculating the costs associated with each consequence severity class.

Table 10. Results of risk assessment, based on assessment of all the scenarios.

\begin{tabular}{|c|c|c|c|c|c|}
\hline \multirow{2}{*}{$\begin{array}{l}\text { Consequence } \\
\text { Class }\end{array}$} & \multicolumn{4}{|c|}{ Contributions from Each of the Return Period Ranges } & \multirow{2}{*}{$\begin{array}{c}\text { Aggregated Probability from All } \\
\text { the Assessments }\end{array}$} \\
\hline & $<10$ Years & 10-60 Years & 60-300 Years & $>300$ Years & \\
\hline Low & $0.9 / \mathrm{yr}$ & $0.078 / \mathrm{yr}$ & $0.0088 / \mathrm{yr}$ & $0.0006 / \mathrm{yr}$ & $0.987 / \mathrm{yr}$ \\
\hline Moderate & $\approx 0$ & $0.0045 / \mathrm{yr}$ & $0.0032 / \mathrm{yr}$ & $0.0004 / \mathrm{yr}$ & $8.1 \cdot 10^{-3} / \mathrm{yr}$ \\
\hline High & $\approx 0$ & $0.0004 / \mathrm{yr}$ & $0.0007 / \mathrm{yr}$ & $0.0012 / \mathrm{yr}$ & $2.3 \cdot 10^{-3} / \mathrm{yr}$ \\
\hline Very high & $\approx 0$ & $0.0004 / \mathrm{yr}$ & $0.0007 / \mathrm{yr}$ & $0.0012 / \mathrm{yr}$ & $2.3 \cdot 10^{-3} / \mathrm{yr}$ \\
\hline Sum & $0.9 / \mathrm{yr}$ & $0.083 / \mathrm{yr}$ & $0.013 / \mathrm{yr}$ & $0.003 / \mathrm{yr}$ & $1 / \mathrm{yr}$ \\
\hline
\end{tabular}

The provided example demonstrates analysis of a malfunctioning asset that could lead to a service disruption. In the given example, the duration of the service disruption (i.e., the recovery time) is linked only to the efforts required after an event to return from a malfunctioning infrastructure to normal operation. However, the recovery time depends also on the resourcefulness of the operator, affecting how the situation is managed.

Another simplification in the example is that the severity of the consequences is defined from the severity and duration of the service disruption only. This would be a good approach if there is no redundancy in the transportation infrastructure, i.e., if no diversion roads exist, if possible diversion roads are flooded as well, or if the diversion roads imply a very long detour. If proper diversion roads exist, the severity of the consequences would be lower than in this example and Table 10 would need to be modified. 


\section{Discussion}

The main tasks of infrastructure engineers are to identify the most vulnerable assets in networks with respect to oncoming threats and prioritize maintenance measures and resources accordingly to the available budget. Here, risk-based approaches applied for terrestrial transportation systems aid the decision-making process of planning and implementation of risk mitigation measures and identification of the most cost-effective mitigation measures. Mitigation measures can encompass more robust design of exposed assets, building of protective structures that can reduce hazards intensities (e.g., landslide and flood protection) or measures to reduce consequences of failure(s). On most occasions, the optimal measure is the one that has an effect on mitigation of a predefined failure mode. Here, the fragility functions pertinent to a failure mode need to be elaborated to cover the range of extreme event intensities and the resistance of the investigated asset in cases with and without applied maintenance measure.

Nevertheless, future work is needed to understand the influence of certain assumptions often made for the quantification of risks in transportation systems. The comprehensive evaluation of quantitative risk of infrastructure failures can be complex as well as being computationally expensive. It requires the simulation of different interrelated processes involving epistemic and aleatory uncertainties. The proposed framework and conceptualization of the risk assessment should be extended to incorporate a quantification of the uncertainties associated with each of the risk components. The risk formulations in this paper are expressed using both deterministic and probabilistic quantities. Uncertainties associated with the vulnerability of the exposed assets are included when fragility curves are applied. In addition, the framework should incorporate uncertainties in the spatial extent and intensity of extreme events, as well as uncertainties associated with the direct and indirect consequences. Uncertainties associated with the indirect consequences are mainly aleatory.

The past applied models usually focused on either evaluation of consequences of failures via traffic macrosimulation $[64,66]$ or analyzing scenarios of multiple object failures, e.g., as in [92]. There are not many methodologies that link infrastructure performance to transport network operations, e.g., as in [93]. Consequently, infrastructure owners are reluctant to implement state-of the-art approaches as the sensible prioritization of investments requires all transportation modes and multiple critical assets to be considered as part of the risk assessment methodology.

Research efforts are needed to link modelling of user's behavior in disrupted transportation systems [69] to spatial and temporal modelling of both hazard and network vulnerability, similarly to [94]. However, as the accuracy of the traffic modelling increases, the computational costs of each simulation increase significantly. For this reason, current risk assessment approaches for transportation networks have limited the analysis to few deterministic scenarios which do not appropriately account for all the uncertainties. Strategies such as importance sampling techniques have been adopted within simulation frameworks aiming to reduce the computational effort [29]. A trade-off between sophisticated models and computational cost is necessary and should depend on results from sensitivity analysis to specify which components of the risk assessment should be analyzed in more detail.

Despite proper risk assessment of the infrastructure, failures and service disruptions may still occur. It is necessary to be prepared for a recovery and to ensure a resilient infrastructure by establishing plans for keeping the functionality of the transportation system under adverse conditions and for a quick restoration of the transportation service after a service disruption induced by an extreme event.

\section{Conclusions}

This paper aims to bridge the gap between general risk assessment frameworks and specific risk assessments of terrestrial transportation infrastructures by proposing a framework that is flexible enough to accommodate different failure modes, asset types and extreme events. The proposed approach improves the identification of risk scenarios 
by providing a comprehensive overview of extreme events and failure modes/modes of malfunctioning. The paper describes and conceptualizes the content of the necessary steps in a quantitative risk assessment of transport infrastructures. The framework is envisioned as a support for practical risk assessment, which is demonstrated through practical examples for assessment of separate risk components. The paper discusses strategies and tools for a quantification of risk components by applying models in literature and using available data sources. Finally, the paper guides and formulates explicitly the integration of the risk components into a risk estimate. The guidance is supported by a risk assessment case study considering flooding of a roadway demonstrating the combination of several assessment steps.

This paper also provides recommendations for the choice of intensity parameters for different extreme events when developing damage, loss and fragility functions. The derivation of a fragility curve for a masonry arch bridge subjected to local foundation scour during river flooding is described in detail as well as all the challenges that were encountered in establishing this curve.

The results from the application of the proposed framework serve as a basic input for a risk-based decision making on preventative maintenance of infrastructure in the face of sudden extreme events. Future work can be directed towards evaluation of competing risk mitigation actions, based on predefined risk acceptance criteria and a cost-benefit analysis, in order to select the optimal maintenance activities on assets in transportation networks.

Author Contributions: Conceptualization, U.E.; software, M.S.; formal analysis, U.E., M.S., N.G., N.T., L.P., R.H.; investigation, N.G.; data curation, N.G.; writing-original draft preparation, U.E., M.S., N.G., N.T., L.P., R.H.; writing-review and editing, U.E., M.S., N.G., N.T., L.P., R.H., F.N., H.S.S., J.M.; visualization, L.P., U.E., M.S., N.G.; supervision, H.S.S., J.M. All authors have read and agreed to the published version of the manuscript.

Funding: The research leading to the results in this paper has received funding from the European Community's H2020 Program MG-7-1-2017, Resilience to extreme (natural and human-made) events, under Grant Agreement number: 769255-“'GIS-based infrastructure management system for optimized response to extreme events of terrestrial transport networks (SAFEWAY)". The support is gratefully acknowledged.

Institutional Review Board Statement: Not applicable.

Informed Consent Statement: Not applicable.

Data Availability Statement: Not applicable.

Conflicts of Interest: The authors declare no conflict of interest.

Disclaimer: The sole responsibility for the content of this publication lies with the authors. It does not necessarily reflect the opinion of the European Union. Neither the Innovation and Networks Executive Agency (INEA) nor the European Commission are responsible for any use that may be made of the information contained herein.

\section{References}

1. Mattsson, L.G.; Jenelius, E. Vulnerability and resilience of transport systems-A discussion of recent research. Transp. Res. Part A 2015, 81, 16-34. [CrossRef]

2. Hackl, J.; Lam, J.C.; Heitzler, M.; Adey, B.; Hurni, L. Estimating network related risks, A methodology and an application in the transport sector. Nat. Hazards Earth Syst. Sci. 2018, 18, 2273-2293. [CrossRef]

3. Dobney, K.; Baker, C.J.; Quinn, A.D.; Chapman, L. Quantifying the effects of high summer temperatures due to climate change on buckling and rail related delays in south-east United Kingdom. Meteorol. Appl. 2009, 16, 245-251. [CrossRef]

4. Kontou, E.; Murray-Tuite, P.; Wernstedt, K. Duration of commute travel changes in the aftermath of Hurricane Sandy using accelerated failure time modeling. Transport. Res. A Policy Pract. 2017, 100, 170-181. [CrossRef]

5. Pregnolato, M.; Ford, A.; Wilkinson, S.M.; Dawson, R.J. The impact of flooding on road transport, A depth-disruption function. Transp. Res. Part D 2017, 55, 67-81. [CrossRef]

6. Eidsvig, U.; Kristensen, K.; Vangelsten, B.V. Assessing the risk posed by natural hazards to infrastructures. Nat. Hazards Earth Syst. Sci. 2017, 17, 481-504. [CrossRef] 
7. Lam, J.C.; Adey, B.T.; Heitzler, M.; Hackl, J.; Gehl, P.; van Erp, N.; D’Ayala, D.; van Gelder, P.; Hurni, L. Stress tests for a road network using fragility functions and functional capacity loss functions. Reliab. Eng. Syst. Saf. 2018, 173, 78-93. [CrossRef]

8. Winter, M.G.; Smith, J.T.; Fotopoulou, S.; Pitilakis, K.; Mavrouli, O.; Corominas, J.; Argyroudis, S. An expert judgement approach to determining the physical vulnerability of roads to debris flow. Bull. Eng. Geol. Environ. 2014, 73, 291-305. [CrossRef]

9. Oberndorfer, S.; Sander, P.; Fuchs, S. Multi-hazard risk assessment for roads, probabilistic versus deterministic approaches. Nat. Hazards Earth Syst. Sci. 2020, 20, 3135-3160. [CrossRef]

10. Mitsakis, E.; Stamos, I.; Papanikolaou, A.; Aifadopoulou, G.; Kontoes, H. Assessment of extreme weather events on transport networks, case study of the 2007 wildfires in Peloponnesus. Nat. Hazards 2014, 72, 87-107. [CrossRef]

11. EEA. Climate Change, Impacts and Vulnerability in Europe 2016, An Indicator-Based Report; European Environment Agency (EEA), 2017. Available online: www.eea.europa.eu (accessed on 19 September 2018).

12. WMO; UNISDR. Disaster Risk and Resilience, UN System Task Team on the Post-2015 UN Development Agenda. 2012. Available online: https://www.un.org/en/development/desa/policy/untaskteam_undf/thinkpieces/3_disaster_risk_resilience. pdf (accessed on 6 June 2021).

13. Chen, L.; Wu, H.; Liu, T. Vehicle collision with bridge piers, A state-of the-art review. Adv. Struct. Eng. 2021, 24, 385-400. [CrossRef]

14. Sha, Y.; Hao, H. Nonlinear finite element analysis of barge collision with a single bridge pier. Eng. Struct. 2012, 41, 63-76. [CrossRef]

15. Wang, W.; Liu, R.; Wu, B. Analysis of a bridge collapsed by an accidental blast loads. Eng. Fail. Anal. 2014, 36, 353-361. [CrossRef]

16. Giuliani, L.; Crosti, C.; Gentili, F. Vulnerability of Bridges to Fire. Bridge Maintenance, Safety, Management, Resilience and Sustainability. In Proceedings of the Sixth International Conference on Bridge Maintenance, Safety and Management, Stresa, Lake Maggiore, Italy, 8-12 July 2012.

17. VTT. Extreme Weather Impacts on Transport Systems. VTT Working Papers 168, EWENT Project Deliverable D1. 2011. Available online: http:/ / www.vtt.fi/publications /index.jsp (accessed on 20 September 2018).

18. Erath, A.L. Vulnerability Assessment of Road Transport Infrastructure. Ph.D. Thesis, ETH, Zürich, Switzerland, 2011. Available online: www.research-collection.ethz.ch/handle/20.500.11850/153072 (accessed on 30 October 2019).

19. Meyer, V.; Becker, N.; Markantonis, V.; Schwarze, R.; van den Bergh, J.C.J.M.; Bouwer, L.M.; Bubeck, P.; Ciavola, P.; Genovese, E.; Green, C.; et al. Review article, Assessing the costs of natural hazards-state of the art and knowledge gaps. Nat. Hazards Earth Syst. Sci. 2013, 13, 1351-1373. [CrossRef]

20. Liu, L.; Yang, D.Y.; Frangopol, D.M. Network-level risk-based framework for optimal bridge adaptation management considering scour and climate change. J. Infrastruct. Syst. 2020, 26, 516. [CrossRef]

21. Santarsiero, G.; Masi, A.; Digrisolo, V.; Picciano, A. The Italian Guidelines on Risk Classification and Management of Bridges, Applications and Remarks on Large Scale Risk Assessments. Infrastructures 2021, 6, 111. [CrossRef]

22. Pregnolato, M. Bridge safety is not for granted-A novel approach to bridge management. Eng. Struct. 2019, 196, 35. [CrossRef]

23. Technical Committee ISO/TC 262, Risk Management. In ISO 31000:2018 Risk Management_Guidelines; ISO (The International Organization for Standardization): Geneva, Switzerland, 2018. Available online: https://www.iso.org/standard/65694.html (accessed on 7 July 2021).

24. Snelder, M.; Calvert, S. Quantifying the impact of adverse weather conditions on road network performance. Eur. J. Transp. Infrastruct. Res. 2016, 1, 128-149.

25. Düzgün, H.S.B.; Lacasse, S. Vulnerability and Acceptable Risk in Integrated Risk Assessment Framework. In Landslide Risk Management; A.A. Balkema Publishers: Vancouver, BC, Canada, 2005.

26. Falermo, S.; Blied, L.; Danielsson, P. Guideline-Part C, GIS-Aided Vulnerability Assessment for Roads-Existing Methods and New Suggestions; Roadapt Report; SGI: Linköping, Sweden, 2015.

27. Koks, E.E.; Bockarjova, M.; de Moel, H.; Aerts, J.C.J.H. Integrated Direct and Indirect Flood Risk Modeling, Development and Sensitivity Analysis. Risk Anal. 2014, 35, 882-900. [CrossRef] [PubMed]

28. Kilanitis, I.; Sextos, A. Integrated seismic risk and resilience assessment of roadway networks in earthquake prone areas. Bull. Earthq. Eng. 2019, 17, 181-210. [CrossRef]

29. Messore, M.M.; Capacci, L.; Biondini, F. Life-cycle cost-based risk assessment of aging bridge networks. Struct. Infrastruct. Eng. 2020, 17, 515-533. [CrossRef]

30. Pregnolato, M.; Winter, A.O.; Mascarenas, D.; Sen, A.D.; Bates, P.; Motley, M.R. Assessing flooding impact to riverine bridges, an integrated analysis. Nat. Hazards Earth Syst. Sci. Discuss. 2020. preprint. [CrossRef]

31. Yang, D.Y.; Frangopol, D.M. Physics-based assessment of climate change impact on long-term regional bridge scour risk using hydrologic modeling, Application to Lehigh River watershed. J. Bridge. Eng. 2019, 24, 13. [CrossRef]

32. Akiyama, M.; Frangopol, D.M.; Ishibashi, H. Toward lifecycle reliability-, risk- and resilience-based design and assessment of bridges and bridge networks under independent and interacting hazards, emphasis on earthquake, tsunami and corrosion. Struct. Infrastruct. Eng. 2019, 16, 26-50. [CrossRef]

33. Ishibashi, H.; Akiyama, M.; Frangopol, D.M.; Koshimura, S.; Kojima, T.; Nanami, K. Framework for estimating the risk and resilience of road networks with bridges and embankments under both seismic and tsunami hazards. Struct. Infrastruct. Eng. 2020, 17, 494-514. [CrossRef] 
34. Argyroudis, S.A.; Mitoulis, S.A.; Winter, M.G.; Kaynia, A.M. Fragility of transport assets exposed to multiple hazards, State-ofthe-art review toward infrastructural resilience. Reliab. Eng. Syst. Saf. 2019, 191, 22. [CrossRef]

35. Kim, H.; Sim, S.H.; Lee, J.; Lee, Y.J.; Kim, J.M. Flood fragility analysis for bridges with multiple failure modes. Adv. Mech. Eng. 2017, 9, 1687814017696415. [CrossRef]

36. Lamb, R.; Aspinall, W.; Odbert, H.; Wagener, T. Vulnerability of bridges to scour, insights from an international expert elicitation workshop. Nat. Hazards Earth Syst. Sci. 2017, 17, 1393-1409. [CrossRef]

37. Tanasic, N. Vulnerability of Reinforced Concrete Bridges Exposed to Local Scour in Bridge Management. Ph.D. Thesis, University of Belgrade, Belgrade, Serbia, 2015.

38. Tsubaki, R.; Bricker, J.D.; Ichii, K.; Kawahara, Y. Development of fragility curves for railway embankment and ballast scour due to overtopping flood flow. Nat. Hazards Earth. Syst. Sci. 2016, 16, 2455-2472. [CrossRef]

39. McKenna, G.; Argyroudis, S.A.; Winter, M.G.; Mitoulis, S.A. Multiple hazard fragility analysis for granular highway embankments, Moisture ingress and scour. Transp. Geotech. 2021, 26, 1143. [CrossRef]

40. Gehl, P.; D'Ayala, D. System loss assessment of bridge networks accounting for multi-hazard interactions. Struct. Infrastruct. Eng. 2018, 14, 1355-1371. [CrossRef]

41. Starossek, U.; Haberland, M. Disproportionate collapse: Terminology and procedures. J. Perform. Constr. Facil. 2010, 24, 519-528. [CrossRef]

42. Van Westen, C.J.; Castellanos Abella, E.A.; Sekhar, L.K. Spatial data for landslide susceptibility, hazards and vulnerability assessment, an overview. Eng. Geol. 2008, 102, 112-131. [CrossRef]

43. Nadim, F. Risk Assessment and Management for Geohazards, Keynote Lecture, 2nd ed.; Symposium on Geotechnical Safety \& Risk; CRC Press/Balkema: Gifu, Japan, 2009; pp. 13-26.

44. Ministerio Para la Transición Ecológica. Available online: https://www.miteco.gob.es/es/agua/temas/gestion-de-los-riesgosde-inundacion/mapa-peligrosidad-riesgo-inundacion/ (accessed on 5 April 2019).

45. AASHTO. LRFD Bridge. Design Specifications; American Association of State Highway and Transportation Officials (AASHTO): Washington, DC, USA, 2012.

46. Hajdin, R.; Kušar, M.; Mašović, S.; Linneberg, P.; Amado, J.; Tanasić, N. WG3 Technical Report, Establishment of a Quality Control Plan. COST TU 1406. 2018. Available online: https:/ /www.tu1406.eu/wp-content/uploads/2018/09/tu1406_wg3_digital_vf.pdf (accessed on 31 October 2018).

47. Li, Z.; Nadim, F.; Huang, H.; Uzielli, M.; Lacasse, S. Quantitative vulnerability estimation for scenario based landslide hazards. Landslides 2010, 7, 125-134. [CrossRef]

48. Cardona, O.D.; van Aalst, M.K.; Birkmann, J.; Fordham, M.; McGregor, G.; Perez, R.; Pulwarty, R.S.; Schipper, E.L.F.; Sinh, B.T. Determinants of risk, exposure and vulnerability. In Managing the Risks of Extreme Events and Disasters to Advance Climate Change Adaptation. In A Special Report of Working Groups I and II of the Intergovernmental Panel on Climate Change (IPCC); Cambridge University Press: London, UK, 2012; pp. 65-108.

49. Schultz, M.T.; Gouldby, B.P.; Simm, J.D.; Wibowo, J.L. Beyond the Factor of Safety, Developing Fragility Curves to Characterize System Reliability; Army Corps of Engineers: Washington, DC, USA, 2010.

50. Schneiderbauer, S.; Calliari, E.; Eidsvig, U.; Hagenlocher, M. The most recent view of vulnerability. In Science for Disaster Risk Management 2017, Knowing Better and Loosing Less; Publications Office of the European Union: Luxembourg, 2017 ; pp. 70-84.

51. Chapman, L.; Thornes, J.E.; Huang, Y.; Cai, X.; Sanderson, V.L.; White, S.P. Modelling of rail surface temperatures, a preliminary study. Theor. Appl. Climatol. 2008, 92, 121-131. [CrossRef]

52. Dobney, K.; Baker, C.J.; Chapman, L.; Quinn, A.D. The future cost to the United Kingdom's railway network of heat-related delays and buckles caused by the predicted increase in high summer temperatures owing to climate change. Proc. Inst. Mech. Eng. Part F 2009, 224, 25-34. [CrossRef]

53. NetworkRail. Route Weather Resilience and Climate Change Adaptation Plans, London North. West.; NetworkRail: London, UK, 2014.

54. Vajda, A.; Tuomenvirta, H.; Juga, I.; Nurmi, P.; Jokinen, P.; Rauhala, J. Severe weather affecting European transport systems, the identification, classification and frequencies of events. Nat. Hazards 2014, 72, 169-188. [CrossRef]

55. Argyroudis, S.A.; Mitoulis, S.A. Vulnerability of bridges to individual and multiple hazards-floods and earthquakes. Reliab. Eng. Syst. Saf. 2010, 210, 107564. [CrossRef]

56. ASTRA. Naturgefahren auf den Nationalstrassen, Risikokonzept. Dokumentation ASTRA 89001, Guidelines; Swiss Federal Roads Office (Bundesamt für Strassen): Bern, Switzerland, 2012.

57. UNSW. Vehicle Stability Testing for Flood Flows; WRL Technical Report 2017/07; Water Research Laboratory, University of New South Wales: New South Wales, Australia, 2017.

58. El-Tawil, S.; Severino, E. Vehicle Collision with Bridge Piers. J. Bridge. Eng. 2005, 10, 637-640. [CrossRef]

59. Pasha, J.; Dulebenets, M.A.; Abioye, O.F.; Kavoosi, M.; Moses, R.; Sobanjo, J.; Ozguven, E.E. A comprehensive assessment of the existing accident and hazard prediction models for the highway-rail grade crossings in the state of Florida. Sustainability 2020, 12, 4291. [CrossRef]

60. Alos-Moya, J.; Paya-Zaforteza, I.; Garlock, M.E.M.; Loma-Ossorio, E.; Schiffner, D.; Hospitaler, A. Analysis of a bridge failure due to fire using computational fluid dynamics and finite element models. Eng. Struct. 2014, 68, 96-110. [CrossRef]

61. Lange, D.; Sjöström, J.; Honfi, D. Losses and Consequences of Large Scale Incidents with Cascading Effects. In EU FP 7 Project CascEff Modelling of Dependencies and Cascading Effects for Emergency; CascEff Project: Vienna, Austria, 2015. 
62. Martins, L.; Silva, V. Development of a fragility and vulnerability model for global seismic risk analyses. Bull. Earthq. Eng. 2020, 7, 8851. [CrossRef]

63. Papathoma-Köhle, M.; Kappes, M.; Keiler, M.; Glade, T. Physical vulnerability assessment for alpine hazards, state of the art and future needs. Nat. Hazards 2011, 58, 645-680. [CrossRef]

64. Erath, A.; Birdsall, J.; Axhausen, K.W.; Hajdin, R. Vulnerability assessment of the Swiss road network. Transp. Res. Rec. 2009, 2137, 118-128. [CrossRef]

65. Pregnolato, M.; Ford, A.; Robson, C.; Glenis, V.; Barr, S.; Dawson, R. Assessing urban strategies for reducing the impacts of extreme weather on infrastructure networks. R. Soc. Open Sci. 2016, 3, 160023. [CrossRef] [PubMed]

66. Tanasic, N.; Ilic, V.; Hajdin, R. Vulnerability assessment of bridges exposed to scour. Transp. Res. Rec. J. Transp. Res. Board 2013, 2360, 36-44. [CrossRef]

67. Santamaria, M.; Arango, E.; Jafari, F.; Sousa, H. SAFEWAY consortium. In Dynamic Risk-Based Predictive Models; SAFEWAY Deliverable 5.1; SAFEWAY Project: Vigo, Spain, 2021.

68. Hoogendoorn, S.; Knoop, V. Traffic flow theory and modelling. In The Transport System and Transport Policy; Edward Elgar Publishing: Cheltenham, UK, 2012; pp. 125-159.

69. Nogal, M.; Honfi, D. Assessment of road traffic resilience assuming stochastic user behaviour. Reliab. Eng. Syst. Saf. 2019, 185, 72-83. [CrossRef]

70. Wardrop, J.G. Some theoretical aspects or road traffic research. Road Eng. Div. Meet. Road Pap. 1952, 36, 325-378. [CrossRef]

71. Syrkov, A.; Høj, N.P. Bridge failures analysis as a risk mitigating tool. In IABSE Symposium, Towards a Resilient Built Environment -Risk and Asset; IABSE: Guimarães, Portugal, 2019; pp. 304-310.

72. Galvão, N.; Matos, J.; Oliveira, D.V. Human Errors induced risk in reinforced concrete bridge engineering. J. Perform. Constr. Facil. 2021, 35, 4 .

73. Proske, D. Bridge. Collapse Frequencies versus Failure Probabilities; Springer International Publishing: Cham, Switzerland, 2018.

74. CEN. EN 1990, Eurocode 0, Basis of Structural Design; European Committee for Standardization (CEN): Brussels, Belgium, 2002.

75. Joint Committee on Structural Safety. Probabilistic Model. Code-Part. 1, Basis of Design. 2001. Available online: https: //www.jcss-lc.org/jcss-probabilistic-model-code/ (accessed on 3 September 2020).

76. Centre for Ecology and Hydrology. Flood Estimation Handbook; Centre for Ecology and Hydrology (Formerly the Institute of Hydrology): Wallingford, UK, 1999.

77. England, J.F.; Cohn, T.A.; Faber, B.A.; Stedinger, J.R.; Thomas, W.O.; Veilleux, A.G.; Kiang, J.E.; Mason, R.R. Guidelines for determining flood flow frequency-Bulletin 17C (ver. 1.1, May 2019). USA Geol. Surv. Tech. Methods 2019, 5, 148. [CrossRef]

78. Tejo, A.R.H. Plano de Gestão da Região Hidrográfica do Tejo Relatório Técnico; Agência Portuguesa do Ambiente (APA): Amadora, Portugal, 2012.

79. Parkes, B.; Demeritt, D. Defining the hundred year flood, A Bayesian approach for using historic data to reduce uncertainty in flood frequency estimates. J. Hydrol. 2016, 540, 1189-1208. [CrossRef]

80. Eidsvig, U.; Piciullo, L.; Ekseth, K.; Ekeheien, C. SAFEWAY consortium. European critical hazards (natural), GIS Map and identification of hot spots of sudden extreme natural hazard events, including database with impact and return periods. In SAFEWAY Deliverable D2.1; SAFEWAY Project: Vigo, Spain, 2019.

81. Zampieri, P.; Zanini, M.A.; Faleschini, F.; Hofer, L.; Pellegrino, C. Failure analysis of masonry arch bridges subject to local pier scour. Eng. Fail. Anal. 2017, 79, 371-384. [CrossRef]

82. Tanasic, N.; Hajdin, R. Management of RC bridges with shallow foundation exposed to local scour. J. Struct. Infrastruct. Eng. 2017, 14, 468-476. [CrossRef]

83. Scozzese, F.; Ragni, L.; Tubaldi, E.; Gara, F. Modal properties variation and collapse assessment of masonry arch bridges under scour action. Eng. Struct. 2019, 199, 109665. [CrossRef]

84. Lagasse, P.F.; Ghosn, M.; Johnson, P.A.; Zevenbergen, L.W.; Clopper, P.E. Risk-Based Approach for Bridge Scour Prediction; National Cooperative Highway Research Program Transportation Research Board National Research Council: Washington, DC, USA, 2013.

85. Uzielli, M.; Lacasse, S.; Nadim, F.; Phoon, K.K. Soil variability analysis for geotechnical practice. Charact. Eng. Prop. Nat. Soils 2007, 22, 1653-1754. [CrossRef]

86. Conde, B.; Matos, J.; Oliveira, D.; Riveiro, B. Probabilistic-based structural assessment of a historic stone arch bridge. Struct. Infrastruct. Eng. 2020, 17, 379-391. [CrossRef]

87. Sheppard, D.M.; Renna, R. Bridge. Scour Manual; State of Florida Department of Transportation: Tallahassee, FL, USA, 2010.

88. Smith, C.; Gilbert, M. Application of discontinuity layout optimization to plane plasticity problems. Proc. R. Soc. A 2007, 463, 2461-2484. [CrossRef]

89. LimitState. Geotechnical Analysis Software. 2019. Available online: https:/ / www.limitstate.com/geo (accessed on 30 January 2021).

90. Ioannou, I.; Rossetto, T.; Grant, D.N. Use of Regression Analysis for the Construction of Empirical Fragility Curves. In Proceedings of the Fifteenth World Conference on Earthquake Engineering, Lisbon, Portugal, 24-28 September 2012.

91. ISO. IEC 31010:2019 Risk Management—Risk Assessment Techniques. Technical Committee, ISO/TC 262 Risk Management. 2019. Available online: https:/ / www.iso.org/standard/72140.html (accessed on 7 July 2021). 
92. Adey, B.; Birdsall, J.; Hajdin, R. Methodology to Estimate Risk Related to Road Links, due to Latent Processes. In Proceedings of the 5th International Conference on Bridge Maintenance, Safety and Management IABMAS, Philadelphia, PA, USA, 11-14 July 2010.

93. Hajdin, R.; Lindenmann, H. Algorithm for the Planning of Optimum Highway Work Zones. J. Infrastruct. Syst. 2007, 13, 202-214. [CrossRef]

94. Pyatkova, K.; Chen, A.S.; Butler, D.; Vojinović, Z.; Djordjević, S. Assessing the knock-on effects of flooding on road transportation. J. Environ. Manag. 2019, 244, 48-60. [CrossRef] [PubMed] 